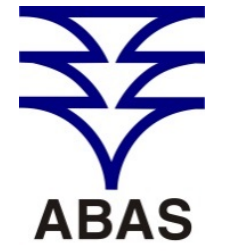

ASSOCIAÇÁB BRASILEIRADE
AGUAS SUBTERRANEAS www.abas.org

\section{TIPOS HIDROQUÍMICOS DO SISTEMA AQUÍFERO BAURU NO ESTADO DE SÃO PAULO}

\author{
HYDROCHEMISTRY TYPES OF THE BAURU AQUIFER SYSTEM IN THE \\ STATE OF SÃO PAULO
}

\author{
Chang Hung Kiang${ }^{1}$; Marcia Regina Stradioto ${ }^{1}$; Flávio Paula e Silva ${ }^{2}$
}

Artigo recebido em: 24/11/2014 e aceito para publicação em: 04/07/2016.

DOI: http://dx.doi.org/10.14295/ras.v30i2.28005

Resumo: A captação de água subterrânea para abastecimento público está presente em 55\% dos municípios brasileiros. No estado de São Paulo, aproximadamente 72\% dos municípios são total ou parcialmente abastecidos por água subterrânea, atendendo a uma população de cerca de 5,5 milhões de pessoas. Nesse contexto, o Sistema Aquífero Bauru ganha relevância por ser um dos mais explorados no interior do estado. O presente trabalho apresenta a caracterização e classificação hidroquímica de quatro unidades aquíferas que compõem esse sistema aquífero em São Paulo. Os estudos foram desenvolvidos na região de ocorrência dos sedimentos cretácicos do Grupo Bauru no estado de São Paulo, com coleta de águas subterrâneas em poços estrategicamente selecionados. A seleção foi direcionada para poços com produção em um único aquífero e regionalmente distribuídos. Aos resultados obtidos foram agregrados dados de análises químicas de trabalhos anteriores, com vistas à obtenção de uma caracterização hidroquímica conjunta para o Sistema Aquífero Bauru. As águas foram classificadas predominantemente como bicarbonatadas cálcicas e sódicas, seguidas de sulfatadas cálcicas e cloretadas sódicas. As águas do Aquífero Caiuá são as menos salinas e e as do Aquífero Santo Anastácio as mais mineralizadas.

Palavras-Chave: Sistema Aquífero Bauru. Hidroquímica. Água Subterrânea.

\begin{abstract}
Groundwater is used for public supply in 55\% of Brazilian municipalities. In the state of São Paulo approximately $72 \%$ of the cities, with an estimated population of 5.5 million inhabitants, are fully or partially supplied by groundwater, being Bauru Aquifer System the most widely used aquifer. This paper presents a hydrochemistry characterization and classification of four aquifer units which comprises the Bauru Aquifer System in the São Paulo state. The studies were carried out in the region of the Cretaceous sedimentary occurrence of the Bauru Group and groundwater sampling was executed in strategically selected water wells. Sampling wells were preferably selected based on single aquifer unit production and regionally distributed. Chemical analyses from previous studies were incorporated in order to provide an integrated hydrochemistry characterization of the Bauru Aquifer System. Calcium and sodium bicarbonate waters are the dominant hydrochemistry types, followed by calcium sulfate and sodium chloride. The Caiuá Aquifer waters are the least saline and those of Santo Anastácio Aquifer the most mineralized.
\end{abstract}

Keywords: Bauru Aquifer System. Hydrochemistry. Groundwater.

\section{INTRODUÇÃO}

O Sistema Aquífero Bauru (SAB) representa uma das principais fontes de explotação de águas subterrâneas no estado de São Paulo. Dentre os 462 municípios paulistas que são abastecidos, parcial ou integralmente, por água subterrânea, aproximadamente 59\% captam água do $\mathrm{SAB}$, sendo que em $88 \%$ deles o abastecimento é feito exclusivamente por água subterrânea (CETESB, 1997). As vazões obtidas em perfurações nesse sistema aquífero são extremamente variáveis em virtude da diversidade litofaciológica do Grupo Bauru, que coloca em contato lateral e vertical sedimentos com diferentes características de porosidade e permeabilidade (Paula e Silva, 2003).

Alguns autores, como Campos

1 UNESP (chang@rc.unesp.br, marciastradioto@uol.com.br)

2 FUNDUNESP (geodata@fpsgeodata.com.br) 
(1987) e Barison (2003) realizaram estudos hidroquímicos nesse sistema aquífero. O primeiro concluiu que as águas subterrâneas do SAB no estado de São Paulo podem ser classificadas em dois tipos dominantes: bicarbonatadas cálcicas e cálcio-magnesianas. Para o autor, essas águas apresentam baixa salinidade, em geral entre $100 \mathrm{mg} / \mathrm{L}$ e $200 \mathrm{mg} / \mathrm{L}$, e os principais íons responsáveis pelo processo de enriquecimento salino das águas subterrâneas da unidade são $\mathrm{HCO}_{3}$, $\mathrm{Ca}$ e Mg. Barison (2003) estudou as águas do SAB na porção meridional do estado e também encontrou predominantemente águas bicarbonatadas cálcicas e cálcio-magnesianas.

Por ser um dos sistemas aquíferos mais explotados no estado, são muitos os trabalhos publicados sobre o SAB. O presente trabalho vem, assim, aprimorar o conhecimento hidroquímico desse sistema, por meio da caracterização química de suas águas subterrâneas, procurando identificar possíveis associações dos tipos hidroquímicos em diferentes unidades aquíferas do SAB. Para esta finalidade, foram realizadas amostragens de águas subterrâneas em 300 poços na área de ocorrência do $S A B$ no estado de São Paulo; além disso, foram utilizados os dados hidroquímicos de Barison (2003) e Stradioto (2007), totalizando 481 pontos de análise.

A área estudada compreende a porção paulista de ocorrência de rochas do Grupo Bauru (Figura 1), com área de aproximadamente $117.000 \mathrm{~km}^{2}(47 \%$ do território paulista), abrangendo 309 municípios e população estimada em cerca de 5.630 .000 habitantes (IBGE, 2010). Esta região é limitada ao norte pelo Rio Grande, a oeste pelo Rio Paraná, a sul pelo Rio Paranapanema e a leste pelas exposições de rochas basálticas da For- mação Serra Geral. Na área afloram as formações Caiuá, Santo Anastácio, Araçatuba, Adamantina e Marília.

\section{SISTEMA AQUÍFERO BAURU NO ES- TADO DE SÃO PAULO}

\subsection{Unidades Aquíferas}

O Grupo Bauru se estende por área de aproximadamente $370.000 \mathrm{~km}^{2}$, distribuídos pelo triângulo mineiro, noroeste do Paraná, sudeste do Mato Grosso do Sul, sul de Goiás e a maior parte do Planalto Ocidental de São Paulo (Figura 1). Em São Paulo, as rochas do Grupo Bauru repousam sobre os basaltos da Formação Serra Geral, por meio de discordância erosiva (Brandt Neto et al., 1977; Soares et al., 1980; Almeida et al., 1981; Riccomini et al., 1981), e localmente sobre sedimentos das formações Botucatu e Pirambóia, como na região de Bauru (SP) (Suguio et al., 1977; Paula e Silva e Cavagutti 1992, 1994). Sua espessura média é de $100 \mathrm{~m}$ e as maiores espessuras preservadas ultrapassam 300 m na região de Marilía (SP).

Soares et al. (1980) propôs a primeira subdivisão estratigráfica formal do Grupo Bauru, que distinguiu as formações Caiuá, Santo Anastácio, Adamantina e Marília com base em suas características litológicas e genéticas. Estudos de subsuperfície realizados por Paula e Silva (2003) e Paula e Silva et al. (2005) mantiveram a subdivisão proposta por Soares et al. (1980), incluindo a Formação Araçatuba; as formações Pirapozinho e Birigui, identificadas com base em perfis geofísicos e descrição de amostras de calhas, foram acrescidas ao Grupo Bauru por esses autores. 


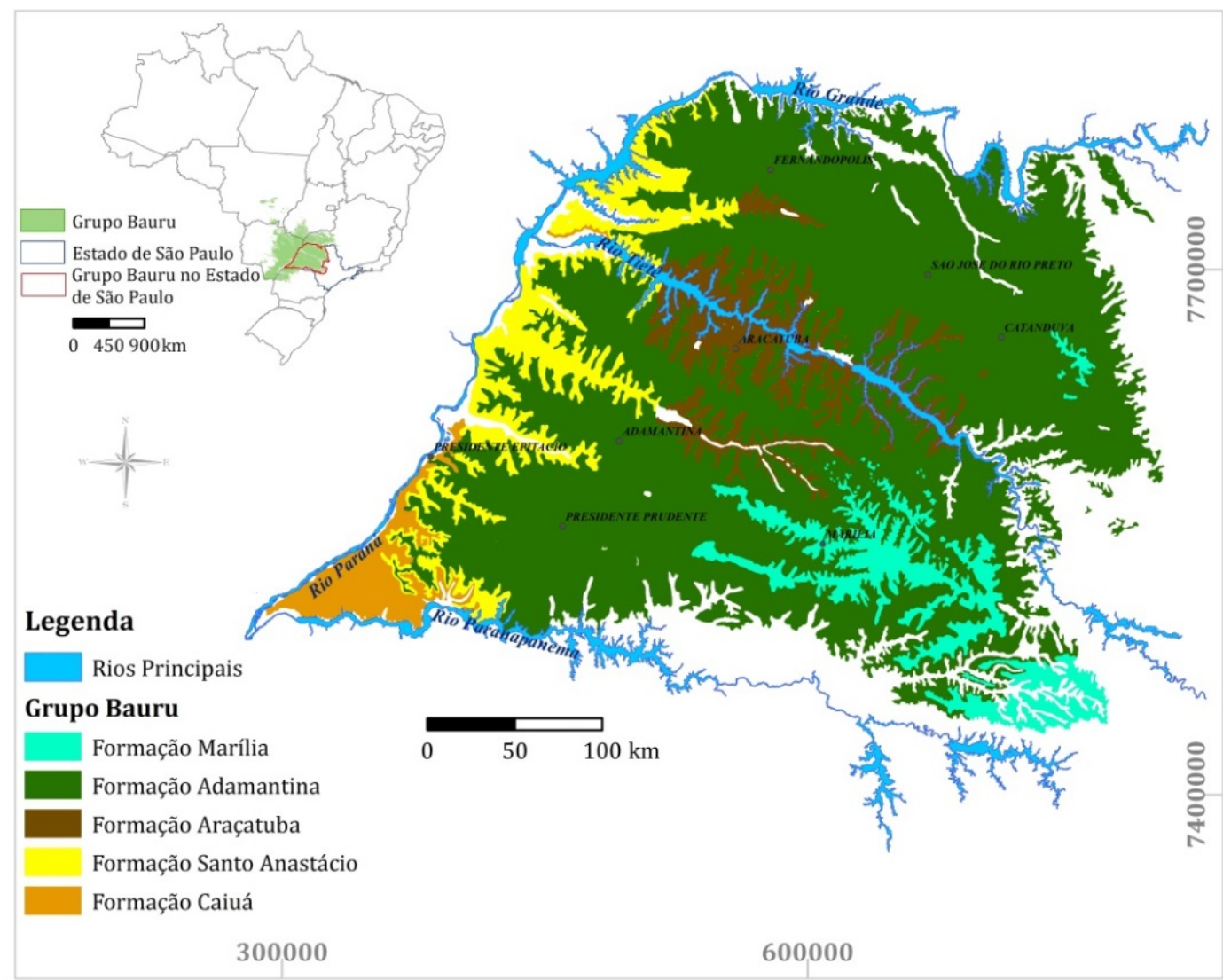

Figura 1 - Mapa geológico do Grupo Bauru no estado de São Paulo, mostrando suas unidades litoestratigráficas aflorantes que correspodem às unidades hidrogeológicas homólogas na área de estudo (modificado de CPRM, 2006)

Figure 1 - Geologic map of the Bauru Group in São Paulo state showing its outcropping lithostratigraphic units which correspond to homologous hydrogeologic units in the study area (modified from CPRM, 2006)

O Sistema Aquífero Bauru comportase como unidade hidrogeológica de extensão regional, contínua, livre e localmente confinada (DAEE, 1974; DAEE, 1976, 1979). Conforme proposta de Paula e Silva (2003) e Paula e Silva et al. (2006), o Sistema Aquífero Bauru divide-se em unidades hidroestratigráficas representadas pelos aquíferos Caiuá, Santo Anastácio, Birigui, Adamantina e Marília, e pelos aquitardos Pirapozinho e Araçatuba.

As vazões registradas para as unidades do SAB são extremamente variáveis, em virtude da diversidade litofaciológica existente que coloca em contato lateral e vertical sedimentos com diferentes características de porosidades e permeabilidades (Paula e Silva, 2003). Esses aspectos foram observados por Vieira (1981), ao destacar que a utilização da expressão “Aquífero Bauru” nem sempre é adequada, já que apresenta mais de um aqui- fero.

As unidades hidroestratigráficas regionais do SAB foram definidas com auxílio de perfis geofísicos de poços tubulares profundos perfurados para captação de água subterrânea no estado de São Paulo (Paula e Silva, 2003 e Paula e Silva et al., 2006). De acordo com esses autores, a subdivisão hidroestratigráfica, fundamentada na litoestratigrafia de subsuperfície, justifica-se em razão das particularidades litológicas de cada formação, as quais, por sua vez, governam as propriedades hidráulicas dessas unidades; com isso, admitiram haver correspondência entre unidades litoestratigráficas e hidroestratigráficas na partição do SAB.

Segundo Paula e Silva (2003) e Paula e Silva et al. (2002, 2003), o Aquífero Caiuá e o Aquitardo Pirapozinho são representados por sedimentos atribuídos às formações homônimas. As fácies psamíticas e pelíticas 
compreendem um inter-relacionamento cíclico, retratado por: a) pacotes de arenitos depositados em ambiente fluvial, com interações eólicas mais proeminentes em direção ao topo da sucessão, e b) pacotes argilo-siltosos depositados em ambiente lacustre, aflorando em pequena extensão na região do Pontal do $\mathrm{Pa}$ ranapanema e nas proximidades do $\mathrm{Rio} \mathrm{Pa}-$ raná. Essas unidades hidroestratigráficas estão encobertas por unidades aquíferas mais jovens no restante dos $31.000 \mathrm{~km}^{2}$ de sua área de ocorrência. O Aquífero Caiuá apresenta extensão regional, é livre e contínuo. Condições de confinamento local são observadas nas porções onde a Formação Pirapozinho intercalase com a Formação Caiuá, ou onde esta última encontra-se encimada por outras unidades aquíferas do SAB.

O Aquífero Santo Anastácio aflora em estreita faixa paralela ao Rio Paraná (Figura 1), mas em subsuperfície avança na direção oriental, estendendo-se por aproximadamente $67.000 \mathrm{~km}^{2}$; é representado pelos sedimentos preponderantemente arenosos da formação homônima, geralmente com raras intercalações pelíticas (Paula e Silva, 2003). O Aquífero Santo Anastácio apresenta extensão regional, é livre e contínuo; possui localmente condições de confinamento nas porções onde está recoberto pelo Aquitardo Araçatuba ou por camadas pelíticas da Formação Adamantina.

Ocupando uma área de aproximadamente $54.600 \mathrm{~km}^{2}$ do estado de São Paulo, o Aquitardo Araçatuba constitui uma barreira de baixa permeabilidade que isola as unidades hidroestratigráficas subjacentes. Na região sudoeste, isola os aquíferos Caiuá e Santo Anastácio; na região central da bacia, interdigita-se com sedimentos da Formação Birigui; nas demais áreas, assenta-se sobre o embasamento basáltico ou cobre localmente o Aquífero Santo Anastácio (Paula e Silva, 2003).

O Aquífero Adamantina ocorre extensivamente em superfície (Figura 1), ocupando uma área de aproximadamente 99.600 $\mathrm{km}^{2}$; apresenta-se coberto apenas localmente pela Formação Marília e ausente, por erosão, no extremo sudoeste paulista. Os depósitos arenosos em fining upward, com terminações em pelitos, são característicos deste aquífero de extensão regional, livre a localmente confinado. O confinamento local é decorrente principalmente das variações de permeabilidade de seus sedimentos, em razão de maior ou menor teor de argila da matriz, ou de camadas pelíticas que se intercalam aos corpos arenosos (Paula e Silva, 2003).

O Aquífero Marília, com área de aproximadamente $15.000 \mathrm{~km}^{2}$, situa-se na porção centro-oriental da área de exposição do Grupo Bauru, entre os rios Tietê e Paranapanema (Figura 1). É representado por sucessão homogênea, predominantemente arenosa, de granulometria fina a grossa, com baixo conteúdo argiloso, intercalações delgadas de material pelítico e zonas com intensa cimentação carbonática; apresenta extensão regional, é livre e localmente confinado. Não raro, a unidade apresenta aquíferos suspensos em zonas de alteração superficiais da unidade devido à presença de estratos subjacentes, relativamente impermeáveis, isolando o corpo aquoso principal (Paula e Silva, 2003).

\subsection{Hidroquímica}

Estudos hidroquímicos das águas do Grupo Bauru no estado de São Paulo realizados por Campos (1987) concluíram que ocorrem dois tipos dominantes: águas bicarbonatadas cálcicas e cálcio-magnesianas. As águas do Aquífero Caiuá, ao contrário das demais unidades aquíferas do Grupo Bauru, são fracamente bicarbonatadas.

As águas do SAB na porção meridional do estado, segundo Barison (2003), são predominantemente bicarbonatadas cálcicas e cálcio-magnesianas. Na Formação Adamantina, as águas foram classificadas principalmente como bicarbonatadas cálcicas e cálciomagnesianas e, em menor proporção, bicarbonatadas sódicas. Os aquíferos Marília e Santo Anastácio apresentaram águas bicarbonatadas cálcicas e cálcio-magnesianas; o Aquífero Caiuá, águas cálcio-magnesianas e sódicas. 
Barison (2003) também encontrou em algumas amostras de águas elevados teores de nitratos que podem estar associados à contaminação antrópica. Segundo Stradioto (2007), nas porções leste, nordeste e central da região sudoeste do estado de São Paulo as águas do SAB são bicarbonatadas sódicas, enquanto as bicarbonatadas cálcicas distribuem-se por toda a área, com discreto predomínio na porção central.

\section{MATERIAIS E MÉTODOS}

Para a caracterização hidroquímica dos aquíferos que formam o Sistema Aquífero Bauru no estado de São Paulo foram coletadas 300 amostras de águas oriundas de 30 poços do Aquífero Marília, 180 do Aquífero Adamantina, 60 do Aquífero Santo Anastácio, 24 do Aquífero Caiuá; outras seis amostras provêm de poços que exploram águas mistas (poços com seções filtrantes em duas ou mais unidades do SAB).

Os dados físico-químicos de Barison (2003) e Stradioto (2007) foram utilizados para complementar a caracterização hidroquímica dos aquíferos do Sistema Bauru. Dos poços coletados por Barison (2003) foram utilizados 135, sendo 16 poços do Aquífero Marília, 68 do Aquífero Adamantina, 5 do Aquífero Santo Anastácio, 10 do Aquífero Caiuá e 36 de poços que exploram águas mistas. Dos poços amostrados por Stradioto (2007), foram usados resultados de 16 poços do Aquífero Santo Anastácio, 8 do Aquífero Caiuá e 22 poços mistos do $\mathrm{SAB}$, totalizando 46 amostras (Figura 2).

A escolha dos poços amostrados na área de estudo (Figura 2) baseou-se em levantamento dos dados construtivos e geológicos desses poços; a informação sobre a posição da seção filtrante em cada poço foi essencial para a identificação da unidade aquífera explotada. Nos poços amostrados por Barison (2003) e Stradioto (2007), utilizados neste estudo, foram analisados os respectivos perfis construtivos para localizar as seções filtrantes desses poços e, com isso, efetuar uma nova caracterização hidroquímica por aquífero. Os dados de perfis construtivos e geológicos dos poços de interesse foram obtidos em bancos de dados de órgãos públicos: Companhia de Pesquisa de Recursos Minerais (CPRM), Companhia de Saneamento Básico do Estado de São Paulo (Sabesp) e Departamento de Águas e Energia Elétrica (DAEE).

Durante a coleta de amostras de água, durante os anos de 2013 e 2014, foram efetuados todos os procedimentos de quantificação de campo, como temperatura, condutividade elétrica e $\mathrm{pH}$, e também o posicionamento geográfico dos poços, com o auxílio de GPS. Ainda em campo, as amostras de água coletadas para análise de cátions e ânions foram filtradas em conjunto Millipore, utilizando filtros de $0,45 \mu \mathrm{m}$. As amostras para análise de cátions no ICP-OES foram acidificadas com ácido nítrico concentrado (7,2 molar), com duas gotas para cada $50 \mathrm{~mL}$ de amostra; os frascos, fechados, foram conservados sob refrigeração para posterior análises físico-químicas.

Para determinação dos elementos Ca, Mg e Si foi utilizado o método de espectrometria de emissão óptica, com fonte de plasma de argônio indutivo (ICP-OES). A alcalinidade $\left(\mathrm{HCO}_{3}{ }^{1-}\right.$ e $\left.\mathrm{CO}_{3}{ }^{2-}\right)$ foi obtida por titulação, os ânions $\left(\mathrm{F}^{1-}, \mathrm{Cl}^{1-}, \mathrm{NO}_{3}{ }^{1-}\right.$ e $\left.\mathrm{SO}_{4}{ }^{2-}\right)$ e os cátions $\left(\mathrm{Na}^{1+}, \mathrm{K}^{1+}\right.$ e $\left.\mathrm{NH}_{4}{ }^{1+}\right)$ foram determinados por cromatografia de íons (IC). As análises químicas foram efetuadas no Laboratório de Hidroquímica do IGCE e no Centro de Estudos Ambientais (CEA), UNESP, Câmpus de Rio Claro, segundo os métodos preconizados por Standard Methods for the Examination of Water and Wastewater (2012).

Para cálculos dos índices de saturação dos minerais foi utilizado o software PHREEQC (Parkhusrst, 1995). O programa de modelagem hidrogeoquímica baseia-se no equilíbrio químico das soluções aquosas com minerais e gases e possibilita a simulação de mistura de águas, trocas iônicas, equilíbrio de soluções sob pressão ou volume constantes, dissolução e precipitação de fases minerais para alcançar o equilíbrio com a fase aquosa. 


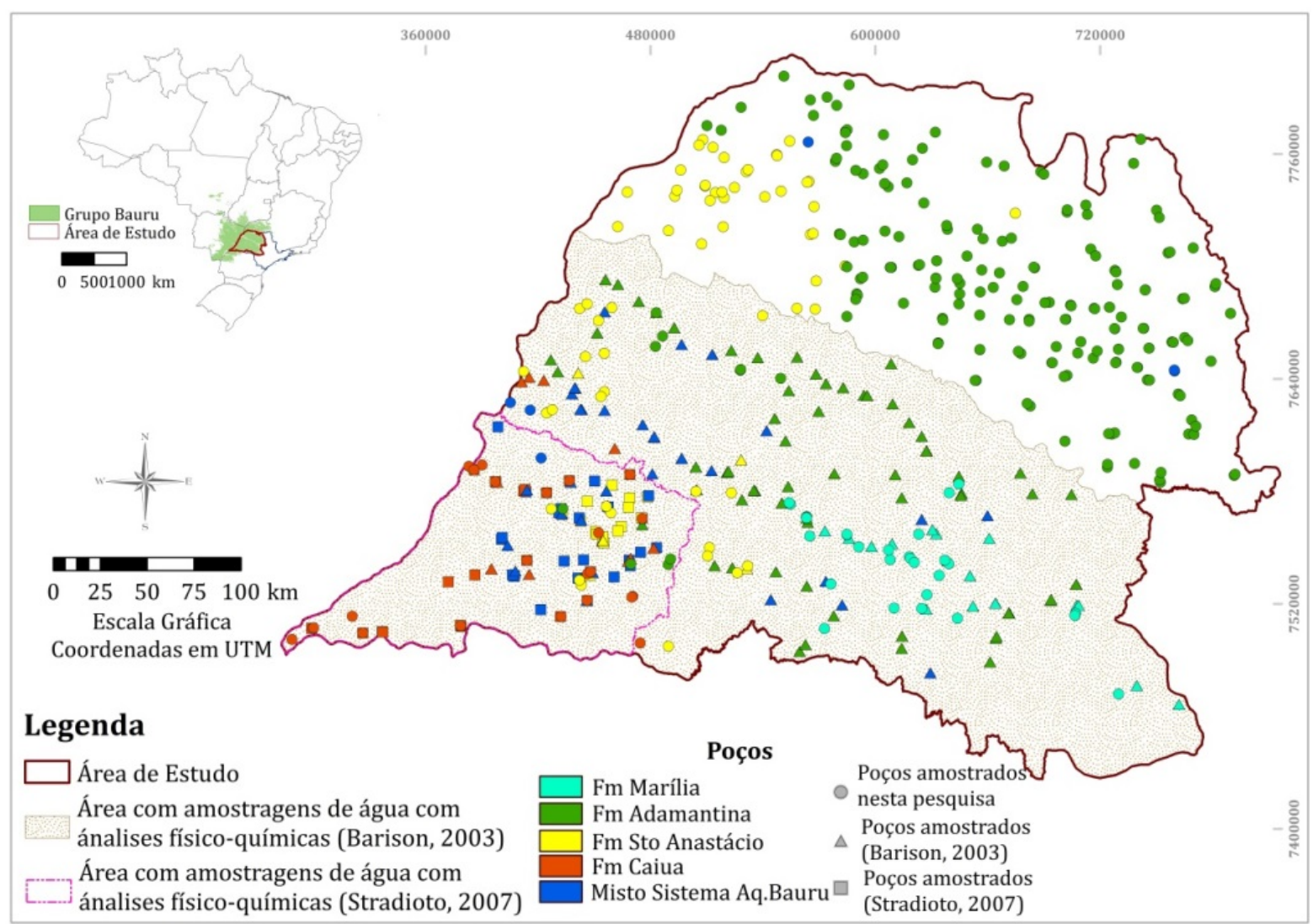

Figura 2 - Localização dos poços amostrados nesta pesquisa e dos poços de Barison (2003) e Stradioto (2007) utilizados neste estudo

Figure 2 - Location of the wells sampled in the present study and those from Barison (2003) and Stradioto (2007)

\section{RESULTADOS E DISCUSSÕES}

\subsection{Classificação das Águas do SAB no es- tado de São Paulo}

A maioria das amostras apresentou balanço de carga com até $20 \%$ de erro, sendo que $94 \%$ das amostras ficaram com erros abaixo de $10 \%$, e $67 \%$ abaixo de 5 . Erros maiores que $10 \%$ podem ser resultado da baixa concentração iônica, que aumenta o erro analítico devido a restrições dos limites de detecção dos equipamentos, sendo esta a hipótese mais provável; podem ainda indicar precipitação de substâncias antes da análise, ou a não inclusão de algumas substâncias presentes dentre os parâmetros quantificados.

A classificação hidroquímica e sua representação foram feitas com auxílio dos diagramas de Piper (Figura 3) e Stiff (Figura 4), atribuindo-se valor zero para íons que ficaram com teor abaixo do limite de detecção do método de análise empregado.

As águas do Aquífero Marilia foram classificadas predominantemente como bicarbonatadas cálcicas (76\%), seguidas pelas bicarbonatadas sódicas (15\%) e sulfatadas cálcicas (9\%) (Figura 3). Das 248 amostras de água do Aquífero Adamantina, 90\% foram classificadas como bicarbonatadas, sendo $76 \%$ cálcicas e $14 \%$ sódicas; os $10 \%$ restantes dividem-se em cloretadas sódicas e sulfatadas cálcicas. As águas do Aquífero Santo Anastácio foram classificadas como bicarbonatadas cálcicas (59\%), bicarbonatadas sódicas (36\%), sulfatadas cálcicas (4\%) e cloretadas sódicas (1\%). Dentre as águas do Aquífero Caiuá, 50\% foram classificadas como bicarbonatadas cálcicas, 26\% como bicarbonatadas sódicas, $14 \%$ como cloretadas sódicas e $10 \%$ 
como sulfatadas cálcicas. Considerando os 64 poços que exploram águas mistas do $\mathrm{SAB}$, $69 \%$ das amostras foram classificadas como bicarbonatadas cálcicas, 27\% como bicarbonatadas sódicas, $3 \%$ como cloretadas sódicas e 1\% como sulfatadas cálcicas (Figura 3).
No geral, as amostras dos aquíferos pertencentes ao SAB são majoritariamente bicarbonatadas, separando-se entre cálcicas (70\%) e sódicas (21\%). A tabela 1 sintetiza os tipos hidroquímicos encontrados nas quatro unidades aquíferas que compõe o SAB.

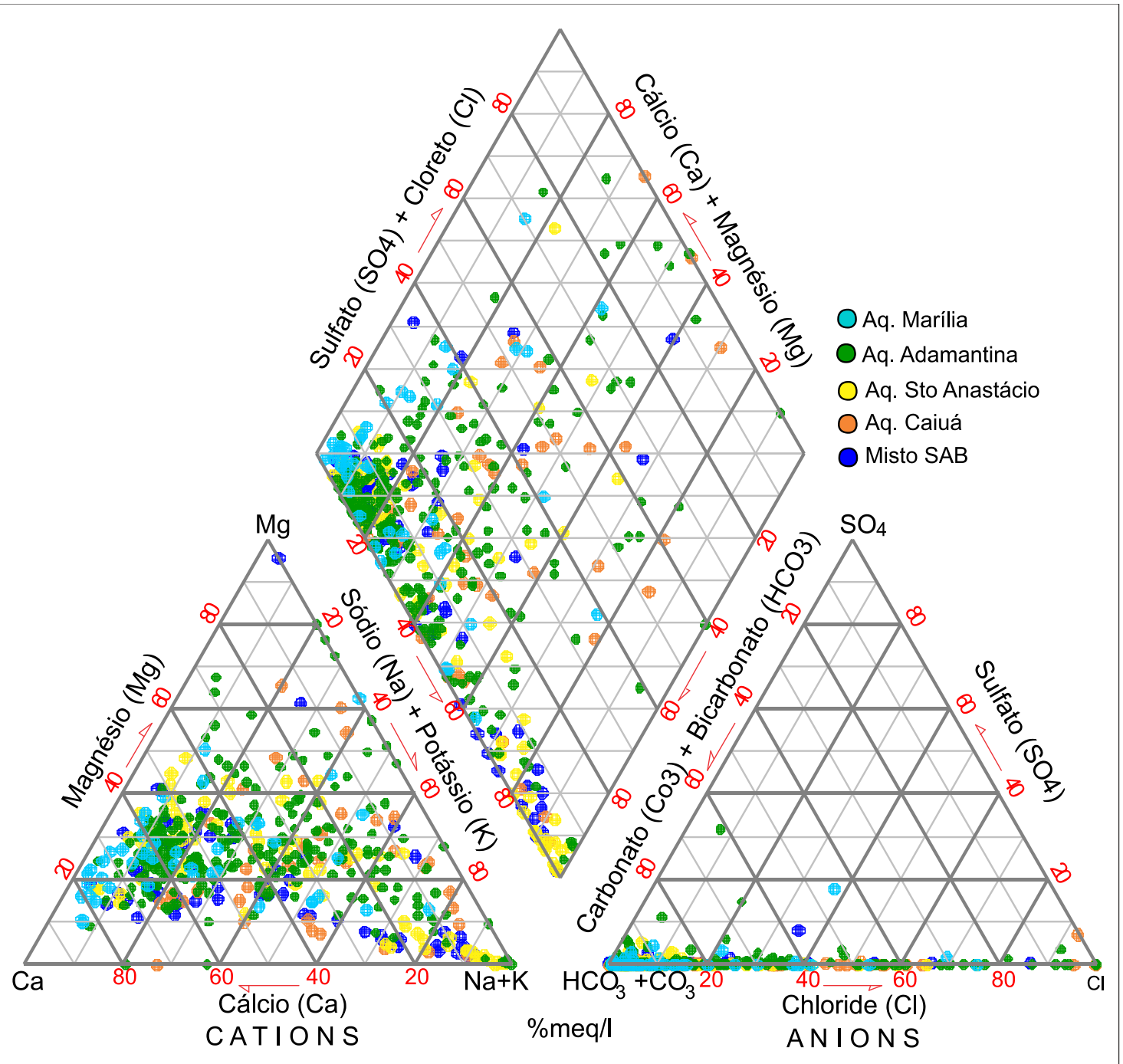

Figura 3 - Diagrama de Piper para amostras de água do Sistema Aquífero Bauru. Neste gráfico estão representadas 300 amostras coletadas para o presente estudo, 135 compilados de Barison (2003) e 46 amostras de Stradioto (2007), totalizando 481

Figure 3 - Piper diagram of Bauru Aquifer System groundwater samples. Of the total 481 samples plotted in the diagram, 300 samples are from the present study, 135 compiled from Barison (2003) and 46 from Stradioto (2007) 
Tabela 1 - Quadro resumo dos principais tipos hidroquímicos determinados para as unidades aquíferas do SAB. Número total de amostras é de 481

Table 1 - Summary of major hydrochemical types determined for SAB aquifer units. Total number of samples is 481

\begin{tabular}{c|c|c|c|c|} 
Unidades Aquíferas & $\begin{array}{c}\text { Bicarbonatada } \\
\text { Cálcica }\end{array}$ & $\begin{array}{c}\text { Bicarbonatada } \\
\text { Sódica }\end{array}$ & $\begin{array}{c}\text { Sulfatada } \\
\text { Cálcica }\end{array}$ & $\begin{array}{c}\text { Cloretada } \\
\text { Sódica }\end{array}$ \\
\hline Marília & $35(76 \%)$ & $7(15 \%)$ & $4(9 \%)$ & $0(0 \%)$ \\
\hline Adamantina & $189(76 \%)$ & $35(14 \%)$ & $12(5 \%)$ & $12(5 \%)$ \\
\hline Santo Anastácio & $48(59 \%)$ & $29(36 \%)$ & $3(4 \%)$ & $1(1 \%)$ \\
\hline Caiuá & $21(50 \%)$ & $11(26 \%)$ & $4(10 \%)$ & $6(14 \%)$ \\
\hline Misto SAB & $44(69 \%)$ & $17(27 \%)$ & $1(1 \%)$ & $2(3 \%)$ \\
\hline Total do SAB & $337(70 \%)$ & $99(21 \%)$ & $24(5 \%)$ & $21(4 \%)$ \\
\hline
\end{tabular}

Os diagramas de Stiff apresentados na Figura 4 evidenciam as diferenças de concentrações iônicas das águas do SAB. As águas coletadas no Aquífero Caiuá (região sudoeste) são em sua maioria menos salinas que as dos demais aquíferos do SAB. As águas do Aquífero Santo Anastácio oriundas da porção noroeste são mais cálcicas, enquanto que as da região sudoeste são mais sódicas. Verifica-se ainda que as águas dos poços localizados nos limites bordas da área de estudo e próximos ao Rio Tietê são menos mineralizadas que as demais.

Na região setentrional do mapa (Figura 4) é possível observar que os diagramas de Stiff possuem, em sua maioria, padrão similar; os íons predominantes nessas amostras são o bicarbonato e o cálcio e os diagramas não mostram diferenças expressivas para os aquíferos Adamantina e Santo Anastácio amostrados nesta região. Na região meridional, as amostras dos aquíferos Adamantina e Caiuá se mostram menos salinas em relação às amostras dos aquíferos Marilia e Santo Anastácio.

\subsection{Análise Estatística de Parâmetros Fí- sico-Químicos e de Composição das Águas Subterrâneas}

A tabela 2 reúne dados estatísticos dos principais parâmetros físico-químicos e composicionais das águas das unidades aquíferas amostradas. As medianas de $\mathrm{pH}$ das amostras de água das unidades aquíferas do SAB são, aproximadamente, 6,73 para o Aquífero Marília, 6,79 para o Aquífero Adamantina, 7,52 para o Aquífero Santo Anastácio, 6,2 para o Aquífero Caiuá e 7,37 para as águas mistas. A figura $5 \mathrm{~A}$ ilustra esses dados, evidenciando que as águas do Aquífero Santo Anastácio são mais alcalinas e as do Aquífero Caiuá mais ácidas. As amostras mistas possuem $\mathrm{pH}$ próximo aos das águas coletadas nos poços que exploram o Aquífero Santo Anastácio.

As medianas de condutividade elétrica das águas analisadas (Figura 5B) são: $182 \mu \mathrm{S} / \mathrm{cm}$ para o Aquífero Marília, 141,9 $\mu \mathrm{S} / \mathrm{cm}$ para o Aquífero Adamantina, 227 $\mu \mathrm{S} / \mathrm{cm}$ para o Aquífero Santo Anastácio, 81,1 $\mu \mathrm{S} / \mathrm{cm}$ para o Aquífero Caiuá e 195,5 $\mu \mathrm{S} / \mathrm{cm}$ para as águas mistas. As águas do Aquífero Caiuá são pouco mineralizadas em relação à dos demais aquíferos amostrados, sendo o valor mínimo encontrado de $6,3 \mu \mathrm{S} / \mathrm{cm}$. A mediana de condutividade elétrica das águas mistas do SAB são próximas às do Aquífero Santo Anastácio. Dentre os 64 poços com águas mistas, 57 possuem filtro no Aquífero Santo Anastácio, fato que deve estar promovendo as semelhanças verificadas.

O bicarbonato é o principal ânion presente nas amostras e o Aquífero Santo Anastácio apresenta o maior valor (Figura 5). Dentre os cátions mais importantes, o cálcio apresenta maior concentração nas amostras 
coletadas, sendo do Aquífero Marilia e dos poços de águas mistas as maiores medianas encontradas, enquanto que o Aquífero Santo

Anastácio possui a maior mediana de sódio (Figura 5).

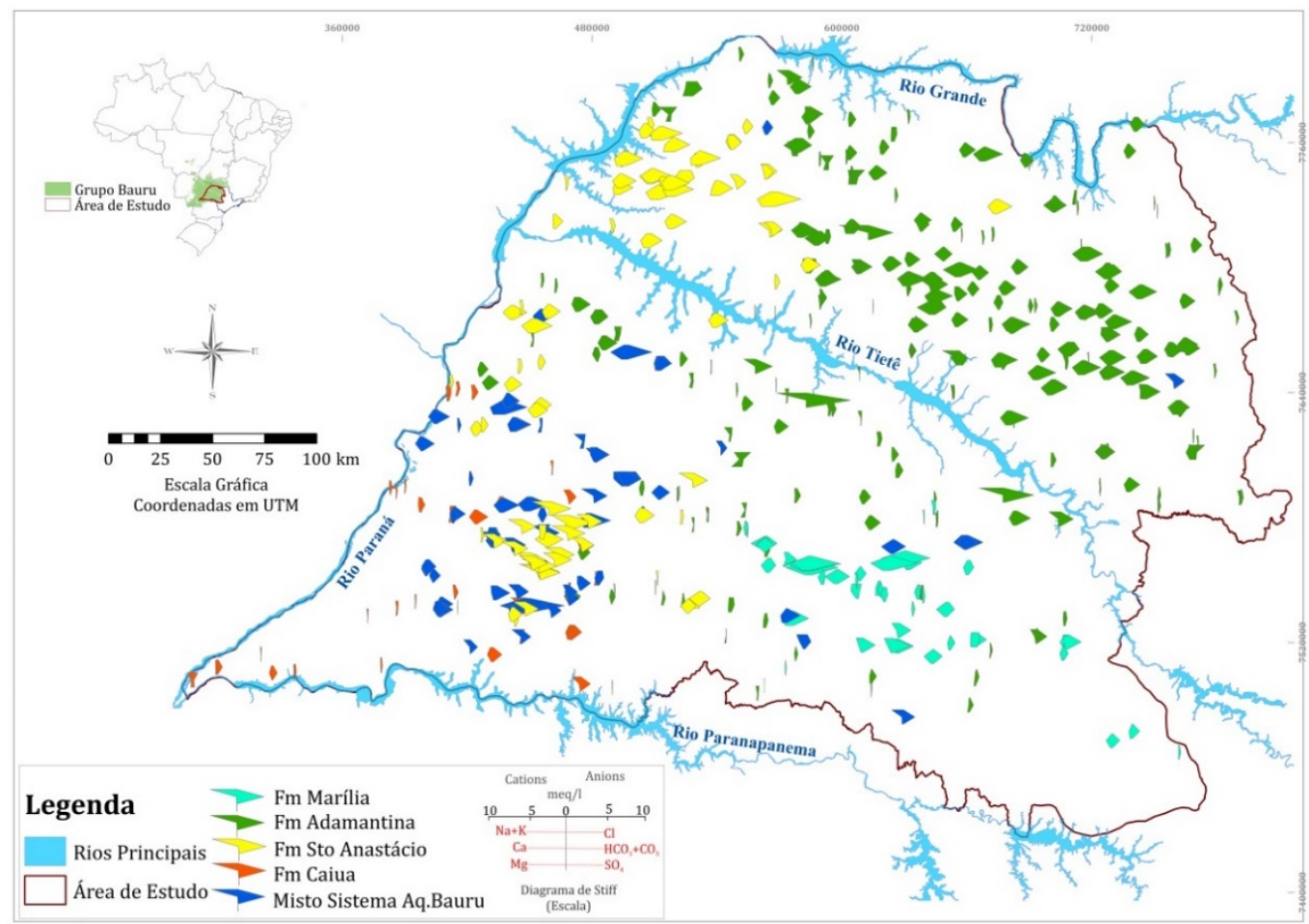

Figura 4 - Diagramas de Stiff de amostras de água das diferentes unidades aquíferas do SAB

Figure 4 - Stiff diagrams of water samples collected from the aquifer units of the SAB

Tabela 2 - Valores máximos, mínimos e tendência central dos resultados físico-químicos das águas dos aquíferos Marília, Adamantina, Santo Anastácio, Caiuá e Misto SAB. Esse último incorpora águas de mais de um intervalo aquífero no poço

Table 2 - Maximum, minimum and central tendency values of water analyses of Marília, Adamantina, Santo Anastácio, Caiuá and mixed SAB aquifers. The latter includes more than one aquifer interval in the well

\begin{tabular}{|c|c|c|c|c|c|c|c|c|c|c|c|c|c|c|}
\hline \multirow{3}{*}{ Aquíferos } & & \multicolumn{13}{|c|}{ Parâmetros } \\
\hline & & \multirow{2}{*}{\begin{tabular}{c|}
$\mathrm{CE}$ \\
$\mu \mathrm{S} / \mathrm{cm}$
\end{tabular}} & \multirow[t]{2}{*}{$\mathrm{pH}$} & STD & $\mathrm{HCO}_{3}$ & $\mathrm{CO}_{3}$ & $\mathbf{F}$ & $\mathrm{Cl}$ & $\mathrm{SO}_{4}$ & $\mathrm{NO}_{3}$ & $\mathrm{Ca}$ & Mg & $\mathrm{Na}$ & K \\
\hline & & & & \multicolumn{11}{|c|}{$\mathrm{mg} / \mathrm{L}$} \\
\hline \multirow{3}{*}{ Marilia } & Mediana & 182,0 & 6,73 & 162,62 & 63,52 & 0,00 & 0,02 & 3,17 & 0,00 & 17,15 & 16,26 & 4,25 & 2,14 & 2,28 \\
\hline & Mínimo & 17,5 & 5,18 & 25,76 & 3,31 & 0,00 & 0,00 & 0,02 & 0,00 & 0,00 & 0,00 & 0,26 & 0,23 & 0,00 \\
\hline & Máximo & 494,0 & 8,98 & 462,62 & 311,00 & 0,00 & 0,55 & 21,00 & 13,70 & 124,00 & 89,34 & 16,50 & 35,70 & 12,50 \\
\hline \multirow{3}{*}{ Adamantina } & Mediana & 141,9 & 6,79 & 148,97 & 47,70 & 0,00 & 0,07 & 2,28 & 0,00 & 10,55 & 9,40 & 3,81 & 4,53 & 3,36 \\
\hline & Mínimo & 6,3 & 4,08 & 6,70 & 0,00 & 0,00 & 0,00 & 0,02 & 0,00 & 0,00 & 0,00 & 0,00 & 0,13 & 0,00 \\
\hline & Máximo & 523,0 & 10,66 & 490,46 & 207,50 & 120,00 & 1,11 & 52,20 & 38,90 & 144,00 & 59,90 & 21,35 & 112,80 & 15,50 \\
\hline \multirow{3}{*}{$\begin{array}{c}\text { Sto } \\
\text { Anastácio }\end{array}$} & Mediana & 218,0 & 7,53 & 214,01 & 101,00 & 0,00 & 0,17 & 2,32 & 0,00 & 6,18 & 12,40 & 3,91 & 7,29 & 3,30 \\
\hline & Mínimo & 9,4 & 5,14 & 14,04 & 1,60 & 0,00 & 0,00 & 0,00 & 0,00 & 0,00 & 0,27 & 0,00 & 0,64 & 0,00 \\
\hline & Máximo & 510,0 & 10,56 & 485,62 & 274,00 & 39,30 & 0,65 & 34,40 & 7,59 & 108,00 & 55,90 & 25,40 & 74,60 & 12,40 \\
\hline \multirow{3}{*}{ Caiuá } & Mediana & 81,1 & 6,20 & 92,54 & 17,85 & 0,00 & 0,06 & 2,86 & 0,00 & 3,95 & 3,31 & 1,31 & 3,64 & 2,48 \\
\hline & Mínimo & 6,3 & 4,36 & 6,74 & 0,00 & 0,00 & 0,00 & 0,00 & 0,00 & 0,00 & 0,13 & 0,00 & 0,05 & 0,01 \\
\hline & Máximo & 267,0 & 9,80 & 253,96 & 156,00 & 44,95 & 0,33 & 23,90 & 2,54 & 85,00 & 25,20 & 10,30 & 57,20 & 10,70 \\
\hline \multirow{3}{*}{$\begin{array}{c}\text { Misto } \\
\text { SAB }\end{array}$} & Mediana & 195,5 & 7,37 & 205,03 & 104,20 & 0,00 & 0,16 & 3,80 & 0,00 & 3,80 & 17,21 & 3,84 & 9,86 & 1,52 \\
\hline & Mínimo & 9,0 & 5,06 & 22,36 & 2,53 & 0,00 & 0,01 & 0,00 & 0,00 & 0,00 & 0,00 & 0,05 & 0,18 & 0,00 \\
\hline & Máximo & 631,0 & 9,97 & 568,43 & 371,70 & 34,50 & 0,54 & 53,50 & 16,20 & 184,00 & 93,69 & 24,03 & 54,30 & 11,52 \\
\hline
\end{tabular}

Águas Subterrâneas (2016) 30(2):224-245 

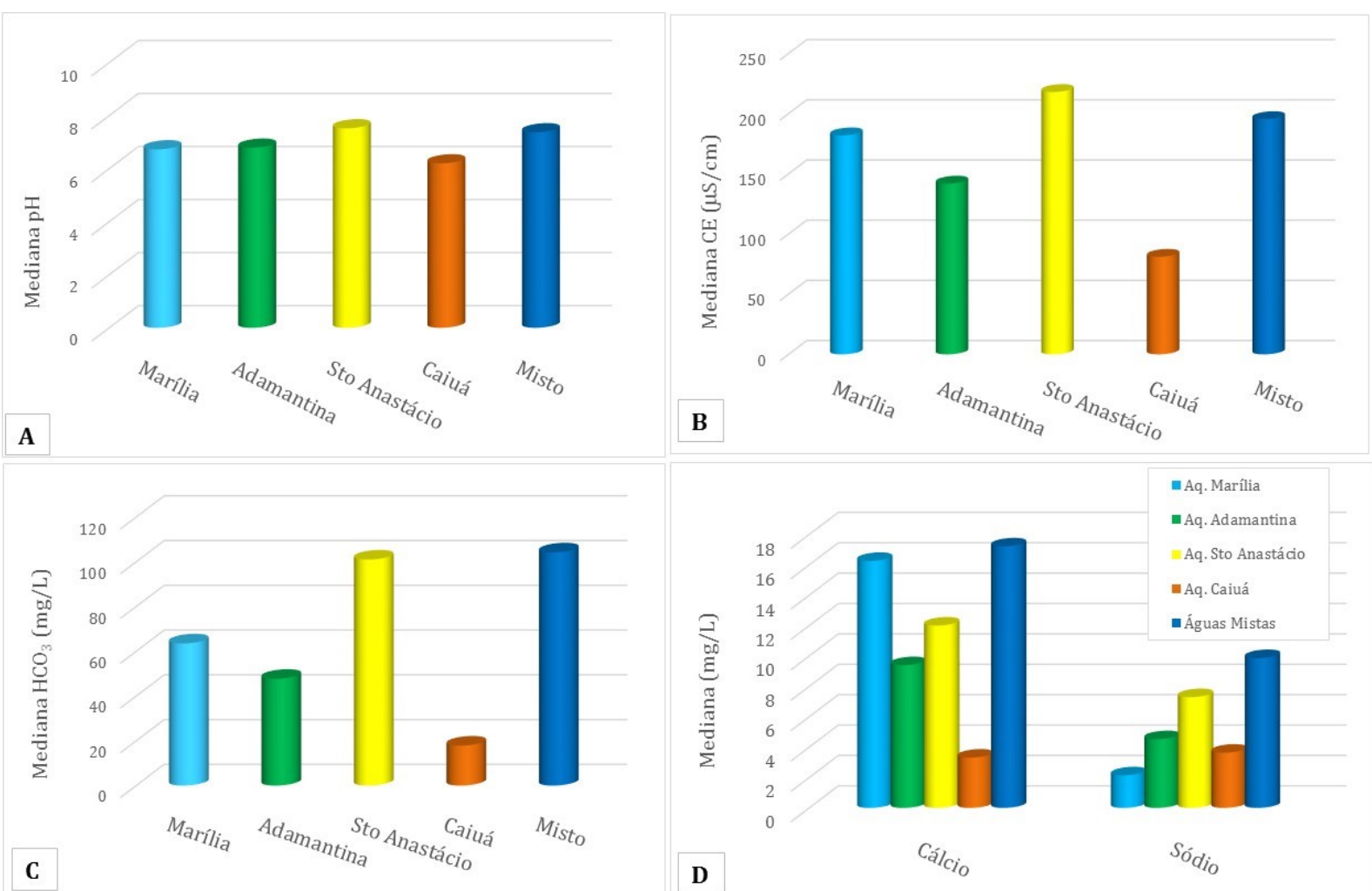

C

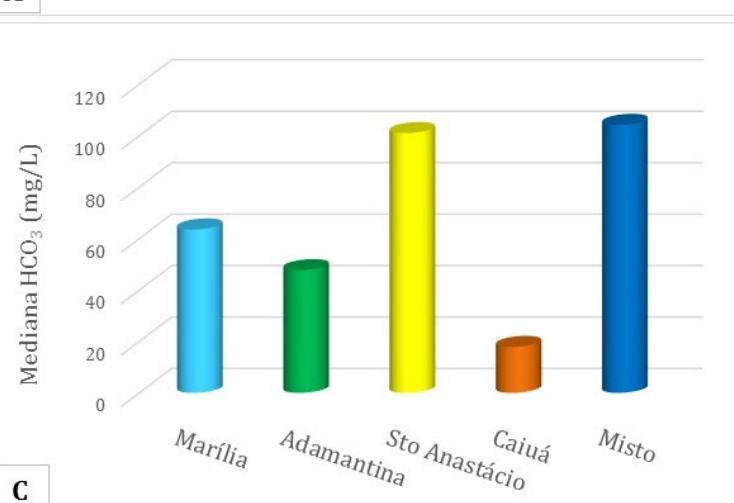

D

Figura 5 - Medianas de $\mathrm{pH}(\mathrm{A})$, condutividade elétrica (B), alcalinidade $\left(\mathrm{HCO}_{3}\right)$ (C) e cálcio e sódio (D) das águas do SAB

Figure 5 - Median values of $\mathrm{pH}(\mathrm{A})$, electrical conductivity (B), alkalinity $\left(\mathrm{HCO}_{3}\right)(\mathrm{C})$ and calcium and sodium (D) for SAB water samples

\subsection{Equilíbrio em Carbonatos}

Um dos principais processos que controlam o ciclo hidrogeoquímico global dos elementos é o intemperismo químico. Nesse ciclo, a água atua como reagente e agente transportador de componentes dissolvidos e particulados; a atmosfera se comporta como um reservatório de dióxido de carbono e oxidantes requeridos para a reação de intemperismo; a biota auxilia o processo de intemperismo, contribuindo com ácidos orgânicos e suprindo localmente, por decomposição, o aumento da concentração de $\mathrm{CO}_{2}$ (STUMM, 1992). O ácido carbônico é formado pela reação do gás carbônico com as moléculas de água: a dissociação pode ocorrer em duas etapas, sendo um próton liberado em cada uma delas; esses prótons agem nos processos de dissolução dos minerais. As reações em que há consumo de $\mathrm{H}^{+} \mathrm{e}$ ao mesmo tempo de $\mathrm{CO}_{2}$ são fundamentais no controle da alcalinidade da água. A reação química simplificada que descreve a dis- solução da calcita é:

$$
\mathrm{CaCO}_{3}+\mathrm{H}^{+}<===>\mathrm{Ca}^{2+}+\mathrm{HCO}_{3}^{1-}
$$

O bicarbonato das águas do Sistema Aquífero Bauru está relacionado ao gás carbônico oriundo das chuvas e do solo e à dissolução de carbonatos e feldspatos. Na figura 6 observa-se a relação entre o índice de saturação em relação à calcita com condutividade elétrica e apresenta predominantemente condições de subsaturação para as águas do SAB na área de estudo.

A insaturação em calcita é característica de aquíferos em sistema aberto, em que as águas meteóricas ácidas e de baixa condutividade elétrica, que percolam formações superficiais, infiltram-se nas rochas e reagem com minerais detríticos. Os resultados obtidos para as águas do SAB corroboram tal situação, uma vez que os poços amostrados não ultrapassam $301 \mathrm{~m}$ de profundidade.

A ocorrência de carbonatos está as-

Águas Subterrâneas (2016) 30(2):224-245 
sociada, geralmente, a águas mais salinizadas. As amostras que apresentam-se supersaturadas em relação à calcita são provenientes principalmente do Aquífero Santo Anastácio ou de mistura de águas de outros aquíferos; essas amostras apresentam também maior salinidade.

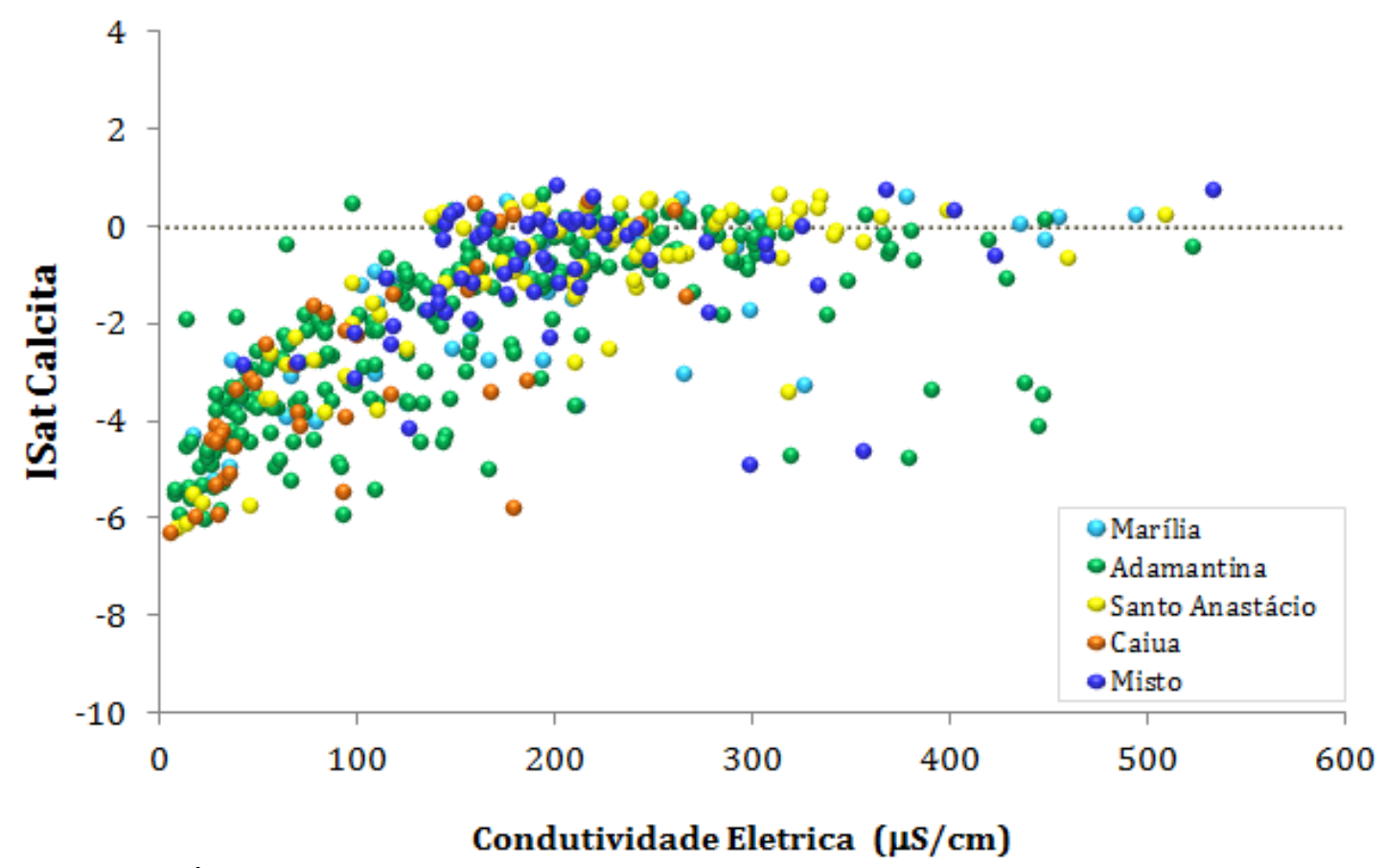

Figura 6 - Índice de saturação de calcita vs. condutividade elétrica em águas do SAB. Misto incorpora águas de mais de um intervalo aquífero no poço

Figure 6 - Saturation index of calcite vs. Electrical conductivity of SAB water samples. Mixed incorporates waters from more than one aquifer interval in a well

\subsection{Equilíbrio em Sílica}

A maior parte da sílica dissolvida em água resulta da reação com minerais silicáticos. Esse processo é irreversível e a sílica dissolvida é controlada por fatores cinéticos nos processos de dissolução, adsorção ou precipitação eodiagenética (HEM, 1985). A concentração observada costuma ser maior que a constante de equlíbrio para o quartzo e menor que a constante de equilíbrio da sílica amorfa, o que sugere, segundo HEM (1985), que outros processos (e não somente a dissolução do quartzo) controlam sua solubilidade, tais como a dissolução de feldspatos, os processos de adsorção, precipitação de minerais secundários e a baixa cinética das reações.

A alteração de minerais silicáticos é lenta, resultando mudanças mais graduais e menos evidentes na química da água em relação a aquíferos carbonáticos (APPELO \& POSTMA, 2005). A reação química simplificada que descreve a dissolução da sílica (quartzo ou sílica amorfa) é:

$$
\mathrm{SiO}_{2}(\mathrm{~s})+2 \mathrm{H}_{2} \mathrm{O}<===>\quad \mathrm{H}_{4} \mathrm{SiO}_{4}
$$

Nas águas do SAB observa-se predomínio de supersaturação em relação à quartzo (Figura 7). Algumas amostras com maiores salinidades apresentam-se insaturadas em quartzo: são amostras principalmente do Aquífero Santo Anastácio, localizadas na porção sudoeste do estado, que foram classificadas como bicarbonatadas sódicas. Essas águas correspondem àquelas em equilíbrio com analcima (Stradioto, 2007; Stradioto et al., 2008). 
De qualquer maneira, a aglomeração de valores de índice de saturação em quartzo próximo de zero (saturação) é coerente com a prevalência de quartzo no arcabouço mineralógico do aquífero. Em condições superficiais do aquífero, a supersaturação é frequente; en- tretanto, não necessariamente ocorre precipitação devido às baixas temperaturas e ao fluxo contínuo de águas subterrâneas. Ou seja, as condições de supersaturação das amostras não implicam em precipitação de sílica (BJORLYKKE \& EGEBERG, 1993)

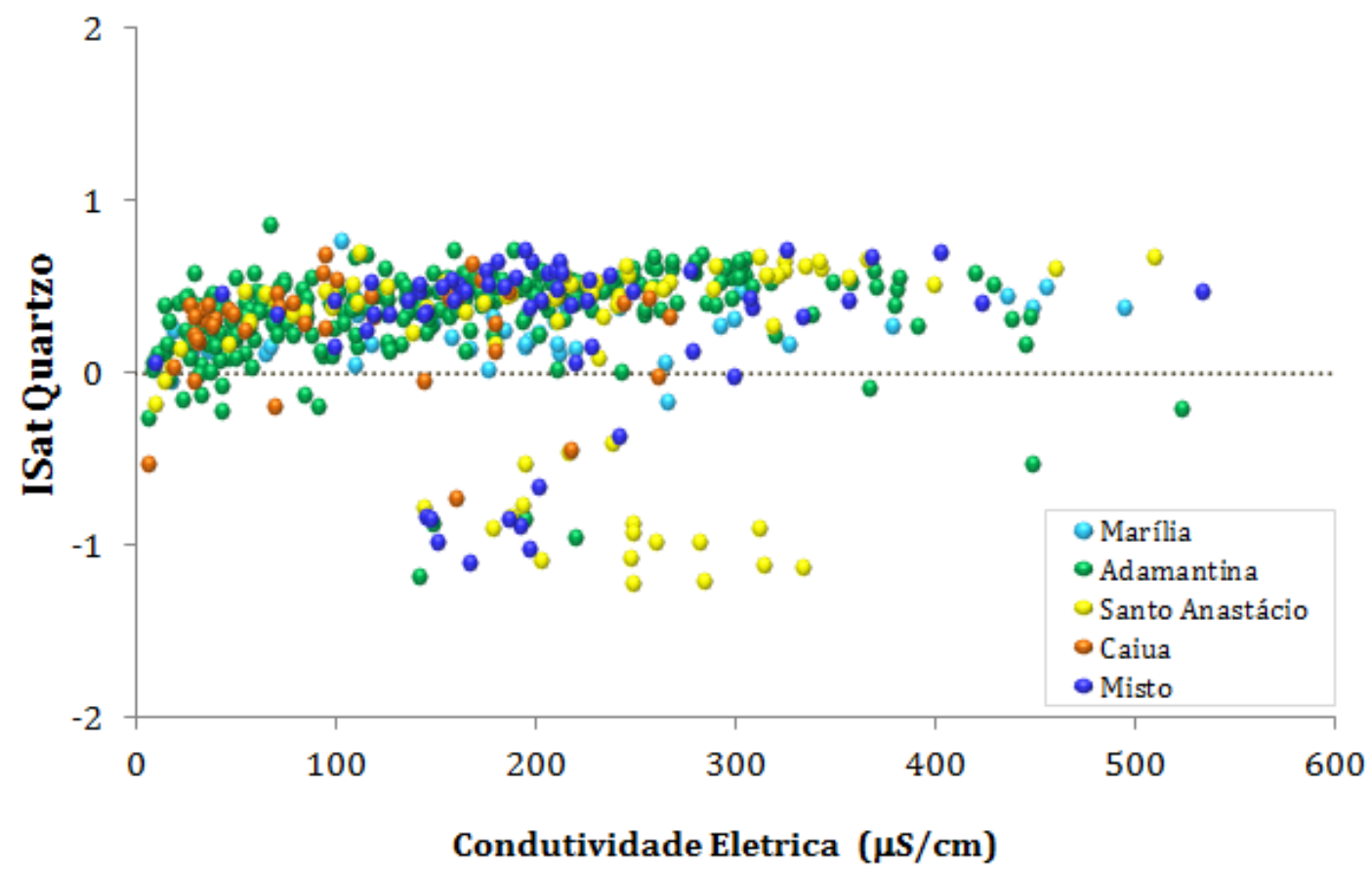

Figura 7 - Índices de saturação de quartzo em águas do SAB. Misto incorpora águas de mais de um intervalo aquífero no poço

Figure 7 - Saturation index of quartz of SAB waters. Mixed incorporates waters from more than one aquifer interval in a well

\subsection{Análise de Agrupamentos}

Nesta análise estatística foram considerados os resultados analíticos em mg/L; os dados não foram normalizados, uma vez que o grau de variabilidade entre os parâmetros analisados é função da própria característica da água e dos processos que resultaram na composição final. Os parâmetros físico-químicos utilizados na análise de agrupamentos estão listados na tabela 1 . O dendrograma foi gerado pela análise de agrupamentos, com uso do método Ward e medida de distância euclidiana (Figura 8). 


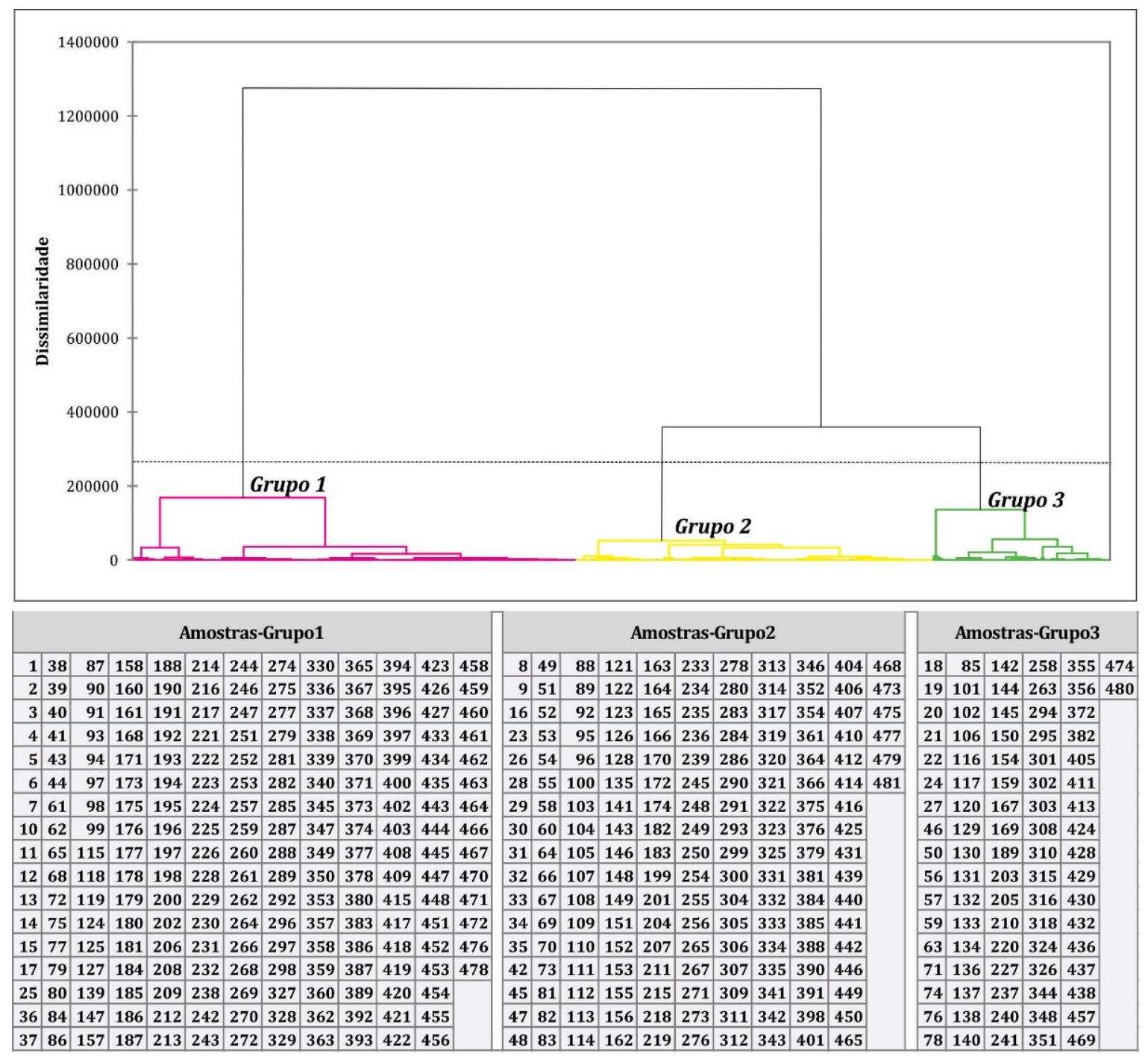

Figura 8 - Grupos identificados pela análise de agrupamentos dos resultados de análises químicas (mg/L) das águas do SAB

Figure 8 - Cluster analysis of chemical analyses from SAB water samples

A análise de agrupamento identificou três grupos distintos de água.

GRUPO 1 - Reúne 218 amostras de águas, sendo 22 do Aquífero Marília, 132 do Aquífero Adamantina, 20 do Aquífero Santo Anastácio, 32 do Aquífero Caiuá e 12 de poços mistos. Essas águas são pouco salinizadas, com sólidos totais dissolvido (STD) predominantemente menores que $150 \mathrm{mg} / \mathrm{L}$ (cerca de $88 \%$ ), com medianas de $83,5 \mathrm{mg} / \mathrm{L}$. O ânion $\mathrm{HCO}_{3}$, ainda que em baixa concentração (até $60 \mathrm{mg} / \mathrm{L}$ e mediana de $16,3 \mathrm{mg} / \mathrm{L}$ ), e $\mathrm{SiO}_{2}$ (até $82,11 \mathrm{mg} / \mathrm{L}$ e mediana de 26,10 mg/L) são as espécies químicas dissolvidas predominantes nestas amostras. Em geral, mantêm a relação para ânions de $\mathrm{HCO}_{3}>\mathrm{NO}_{3}>\mathrm{Cl}$ e para cátions $\mathrm{Ca} \geq \mathrm{K}>\mathrm{Na} \geq \mathrm{Mg}$. Cabe ressaltar que este grupo apresenta várias amostras com elevado teor de nitrato, muitas delas (cerca de 20\%) ultrapassando o limite máximo permitido pela Portaria 2914/11 do Ministério da Saúde (44 mg/ $\mathrm{L} \mathrm{NO}_{3}$ ). Este grupo está distribuído por toda área do SAB no estado de São Paulo (Figura 9), representando principalmente as amostras do Aquífero Caiuá (região sudoeste) e do Aquífero Adamantina, especialmente as localizadas próximas ao rio Tietê e aos limites norte e nordeste da área de pesquisa.

GRUPO 2 - Neste grupo estão 176 amostras, 
sendo 15 do Aquífero Marília, 84 do Aquífero Adamantina, 32 do Aquífero Santo Anastácio, 9 do Aquífero Caiuá e 36 de poços mistos. Estas águas são mais mineralizadas que as do grupo 1. Os valores de sais totais dissolvidos estão, em sua maioria (89\%), entre $150 \mathrm{mg} / \mathrm{L}$ e $370 \mathrm{mg} / \mathrm{L}$, com mediana de $193 \mathrm{mg} / \mathrm{L}$. Predominam nestas águas o ânion $\mathrm{HCO}_{3}$, com mediana de 94,6 mg/L, e o cátion cálcio, com mediana de $20 \mathrm{mg} / \mathrm{L}$. As relações dos íons principais são, em geral, $\mathrm{HCO}_{3}>>\mathrm{NO}_{3}>\mathrm{Cl}$ $>$ F para ânions e $\mathrm{Ca}>\mathrm{Na}>\mathrm{Mg}>\mathrm{K}$ para cátions. As concentrações de nitrato em algumas amostras deste grupo são elevadas, sendo que 10 amostras ultrapassam o limite máximo permitido pela Portaria 2914/11 do Ministério da Saúde (44 mg/L). Embora as amostras deste grupo estejam distribuídas por toda área de estudo, concentram-se preferencialmente nas porções setentrional, principalmente em amostras do Aquífero Adamantina, e sudoeste da área, principalmente em amostras do Aquífero Marília (Figura 9).
GRUPO 3 - Reúne 87 amostras, sendo 9 do Aquífero Marília, 32 do Aquífero Adamantina, 29 do Aquífero Santo Anastácio, 1 do Aquífero Caiuá e 16 de poços mistos. As amostras deste grupo são em geral mais salinas, com sais totais dissolvidos acima de 215 $\mathrm{mg} / \mathrm{L}$ e mediana de $297 \mathrm{mg} / \mathrm{L}$. O ânion $\mathrm{HCO}_{3}$ é o principal íon, com valores acima de 115 $\mathrm{mg} / \mathrm{L}$ e mediana de $157 \mathrm{mg} / \mathrm{L}$; a relação dos ânions é geralmente $\mathrm{HCO}_{3}>>\mathrm{NO}_{3}>\mathrm{Cl}>\mathrm{F}$. O cálcio aparece como o cátion principal com mediana de $35 \mathrm{mg} / \mathrm{L}$; a relação dos cátions neste grupo é, na maioria das vezes, $\mathrm{Ca}>\mathrm{Mg}$ $>\mathrm{Na}>\mathrm{K}$. Neste grupo também ocorrem amostras que ultrapassam o limite máximo permitido pela Portaria 2914/11 do Ministério da Saúde para os íons nitrato (nove amostras). Este grupo se distribuiu principalmente na porção oeste da área de estudo, sendo representado principalmente por águas do Aquífero Santo Anastácio, na região noroeste (Figura 9).

A tabela 3 resume as principais caractéristicas da análise de agrupamento.

Tabela 3 - Resumo das principais características dos três grupos de água subterrâneas discriminados pela análise de agrupamento

Table 3 - Summary of main characteristics of the three groundwater groups defined by the cluster analysis

\begin{tabular}{|c|c|c|c|c|c|c|c|}
\hline \multirow{2}{*}{ GRUPOS } & \multirow{2}{*}{$\begin{array}{c}\text { No. } \\
\text { Amostras }\end{array}$} & \multirow{2}{*}{$\begin{array}{l}\text { Aquíferos } \\
\text { (amostras) }\end{array}$} & \multirow{2}{*}{ STD(mg/L) } & \multirow{2}{*}{$\begin{array}{c}\text { Ânion } \\
\text { Principal } \\
\text { (mg/L) }\end{array}$} & \multirow{2}{*}{$\begin{array}{c}\text { Cátion } \\
\text { Principal } \\
\text { (mg/L) }\end{array}$} & \multicolumn{2}{|c|}{ Relação Iônica } \\
\hline & & & & & & Ânions & Cátions \\
\hline \multirow{5}{*}{1} & \multirow{5}{*}{218} & Marília (22) & \multirow{5}{*}{$\begin{array}{l}<150(88 \%) \\
\text { Medianas }=83,5\end{array}$} & \multirow{5}{*}{$\begin{array}{l}\mathrm{HCO}_{3} \\
\text { Máximo = 60 } \\
\text { Mediana }=16,3\end{array}$} & \multirow{5}{*}{$\begin{array}{l}\text { Ca } \\
\text { Máximo }=33,6 \\
\text { Mediana }=3,43\end{array}$} & \multirow{5}{*}{$\begin{array}{c}\mathrm{HCO}_{3}>\mathrm{NO}_{3} \\
>\mathrm{Cl}\end{array}$} & \multirow{5}{*}{$\begin{aligned} \mathrm{Ca} & \geq \mathrm{K}>\mathrm{Na} \\
& \geq \mathrm{Mg}\end{aligned}$} \\
\hline & & Adamantina (132) & & & & & \\
\hline & & Sto Anastácio (20) & & & & & \\
\hline & & Caiuá (32) & & & & & \\
\hline & & Misto (12) & & & & & \\
\hline \multirow{5}{*}{2} & \multirow{5}{*}{176} & Marília (15) & \multirow{5}{*}{$\begin{array}{l}150 \text { a } 370(89 \%) \\
\text { Medianas }=193\end{array}$} & \multirow{5}{*}{$\begin{array}{l}\mathrm{HCO}_{3} \\
\text { Máximo = 127 } \\
\text { Mediana = 94,6 }\end{array}$} & \multirow{5}{*}{$\begin{array}{l}\text { Ca } \\
\text { Máximo }=49,2 \\
\text { Mediana }=20\end{array}$} & \multirow{5}{*}{$\begin{array}{c}\mathrm{HCO}_{3} \gg \\
\mathrm{NO}_{3}>\mathrm{Cl}>\mathrm{F}\end{array}$} & \multirow{5}{*}{$\begin{array}{c}\mathrm{Ca}>\mathrm{Na}> \\
\mathrm{Mg}>\mathrm{K}\end{array}$} \\
\hline & & Adamantina (84) & & & & & \\
\hline & & Sto Anastácio (35) & & & & & \\
\hline & & Caiuá (09) & & & & & \\
\hline & & Misto (36) & & & & & \\
\hline \multirow{5}{*}{3} & \multirow{5}{*}{87} & Marília (09) & \multirow{5}{*}{$\begin{array}{l}>215(100 \%) \\
\text { Medianas }=297\end{array}$} & \multirow{5}{*}{$\begin{array}{l}\mathbf{H C O}_{3} \\
\text { Máximo = } 372 \\
\text { Mediana = } 157\end{array}$} & \multirow{5}{*}{$\begin{array}{l}\text { Ca } \\
\text { Máximo }=93,7 \\
\text { Mediana }=35\end{array}$} & \multirow{5}{*}{$\begin{aligned} \mathrm{HCO}_{3} & \gg \mathrm{NO}_{3} \\
>\mathrm{Cl} & >\mathrm{F}\end{aligned}$} & \multirow{5}{*}{$\begin{array}{c}\mathrm{Ca}>\mathrm{Mg}> \\
\mathrm{Na}>\mathrm{K}\end{array}$} \\
\hline & & Adamantina (32) & & & & & \\
\hline & & Sto Anastácio (29) & & & & & \\
\hline & & Caiuá (01) & & & & & \\
\hline & & Misto (16) & & & & & \\
\hline
\end{tabular}




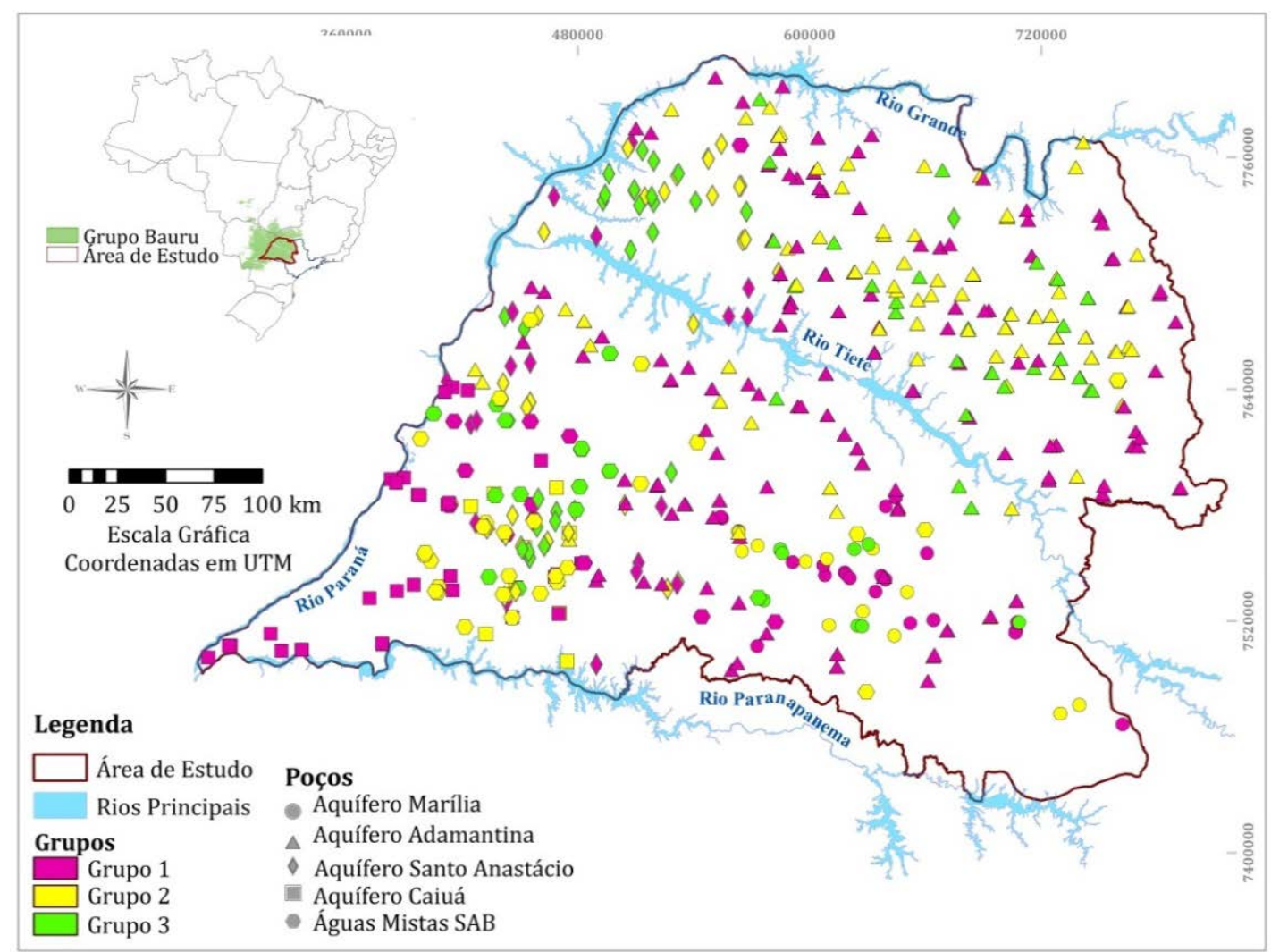

Figura 9 - Distribuição dos grupos hidroquímicos identificados pela análise de agrupamentos das amostras de água do $\mathrm{SAB}$

Figure 9 - Distribution of hydrochemical group defined by the cluster analysis of SAB water samples

O parâmetro determinante dos grupos hidroquímicos é a salinidade que aumenta progressivamente do grupo 1 ao 3 , acompanhado de aumento do bicarbonato, ânion principal, e de cálcio, cátion principal (Figura 10). Em direção contrária, o nitrato diminui sobremaneira nas águas dos grupos 1 ao 3 . Esse aumento na salinidade é em grande parte controlada pelo incremento na profundidade final dos poços amostrados e, por conta do aumento tanto do $\mathrm{HCO}_{3}$ quanto do $\mathrm{Ca}$, as águas tor- nam-se saturadas e super-saturadas em relação à calcita, isto é, o logaritmo do índice de saturação (IS) é igual ou maior que zero (positivo), respectivamente (Figura 11). Quanto à saturação em relação ao quartzo, a grande maioria das águas está em equilíbrio ou supersaturado com relação ao quartzo (Log IS $\geq 0$ ). As amostras subsaturadas correspondem aquelas em equilíbrio com a analcima, conforme descrito anteriormente. 


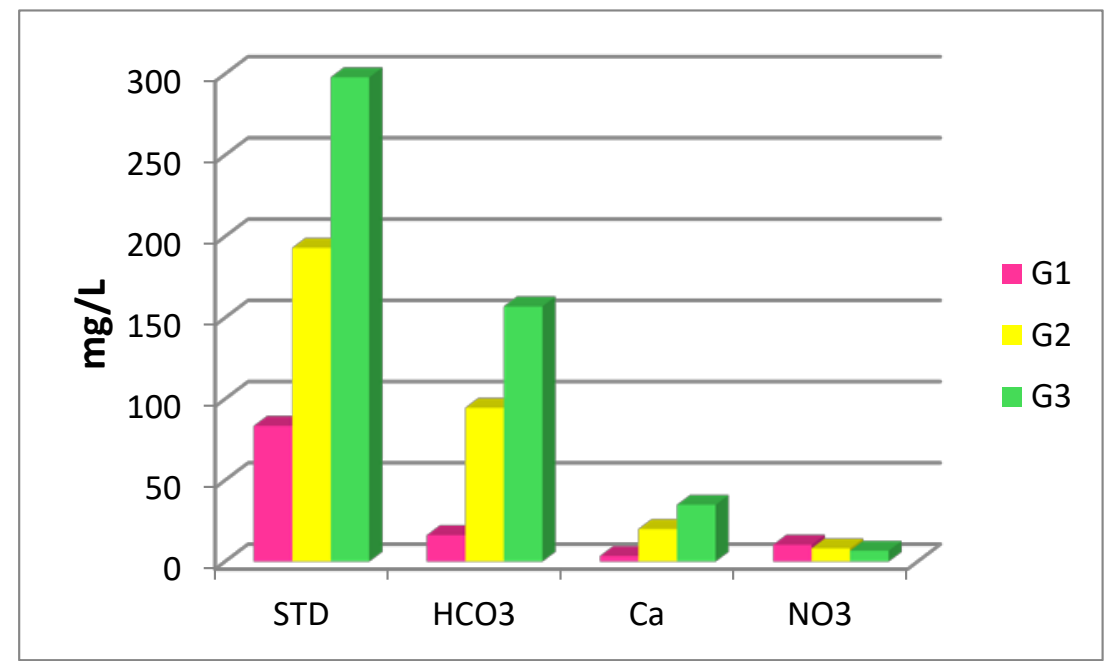

Figura 10 - Valores de mediana de salinidade (STD), $\mathrm{HCO}_{3}, \mathrm{Ca}$ e $\mathrm{NO}_{3}$ dos 3 grupos hidroquímicos identificados pela análise de agrupamento para os poços amostrados do SAB. Notar que somente a concentração de $\mathrm{NO}_{3}$ diminui em direção ao grupo 3

Figure 10 - Median values of salinity (TDS), $\mathrm{HCO}_{3}, \mathrm{Ca}$ e $\mathrm{NO}_{3}$ of 3 hydrochemical groups defined by the cluster analysis of $\mathrm{SAB}$ samples wells. Note only $\mathrm{NO}_{3}$ concentration diminish towards Group 3

Examinando-se o comportamento dos mesmos parâmetros relevantes para classificação dos grupos hidroquímicos, nota-se que não há uma clara correlação entre as unidades aquíferas e os grupos hidroquímicos. Águas em cada unidade aquífera amostrada ocorrem em ampla faixa de profundidades e graus de saturação. No entanto, é possível verificar que poços mais profundos predominam nas unidades aquíferas Marília e Santo Anastácio, com maior frequência para os de Santo Anastácio, e a prevalência de poços rasos para a unidade aquífera Adamantina, seguida pela Marília (Figura 12). Essa situação pode (estar relacionada) ser explicada pela maior exten- são da área aflorante da Formação Adamantina no estado de São Paulo e pela posição estratigráfica mais superior dessa unidade aquífera. Em contraposição, a unidade Santo Anastácio é estratigraficamente inferior e de extensão da área aflorante menor.

Quanto à saturação em relação à calcita, observa-se uma leve tendência de aumento de águas saturadas e supersaturadas, isto é, em equilíbrio com a calcita, nos aquíferos Marília, Santo Anastácio e águas mistas do SAB. Já com relação ao quartzo, todas as unidades apresentam-se com predomínio de águas em equilíbrio com o quartzo (Figura 12). 


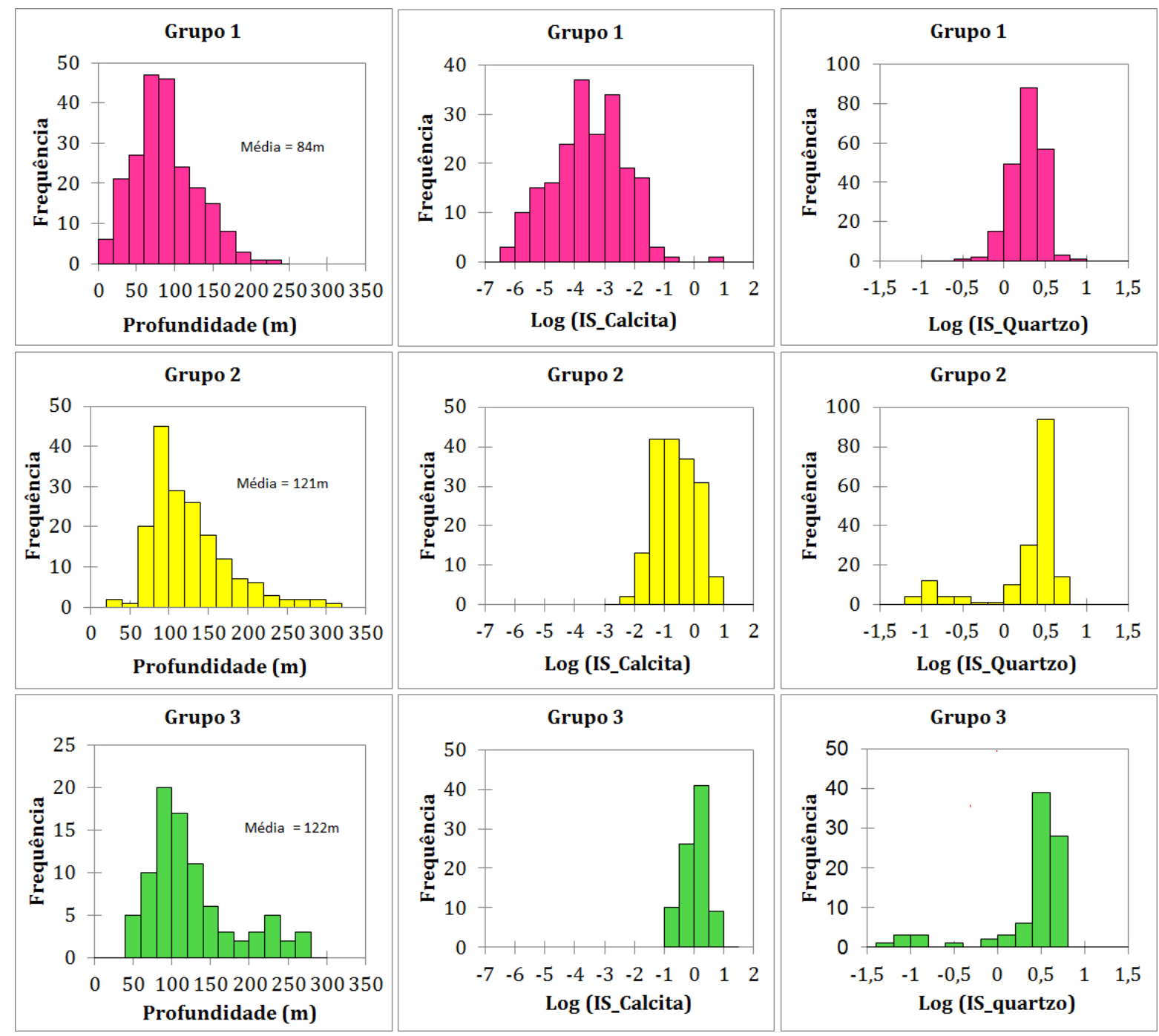

Figura 11 - Histogramas de profundidade e grau de saturação das águas em relação a calcita e quartzo para os três grupos hidroquímicos do SAB. Notar o incremento percentual de poços mais profundos nas amostras de água dos grupos 2 e 3 . A proporção de poços de águas saturadas ou supersaturadas em relação à calcita $(\log (\mathrm{IS}) \geq 0$ ) aumenta do grupo 1 para o 3. Quanto ao quartzo, a maioria dos poços estão saturados/supersaturados

Figure 11 - Histograms of depth and degree of saturation with respect to calcite and quartz for the three hydrochemical groups of SAB. Note the percentage increase in the deeper wells in the groups 2 and 3 . Number of wells saturated or supersaturated with respect to calcite (log (IS) $\geq 0$ ) increases from group 1 to 3 . With respect to quartz majority of wells are saturated or supersaturated 


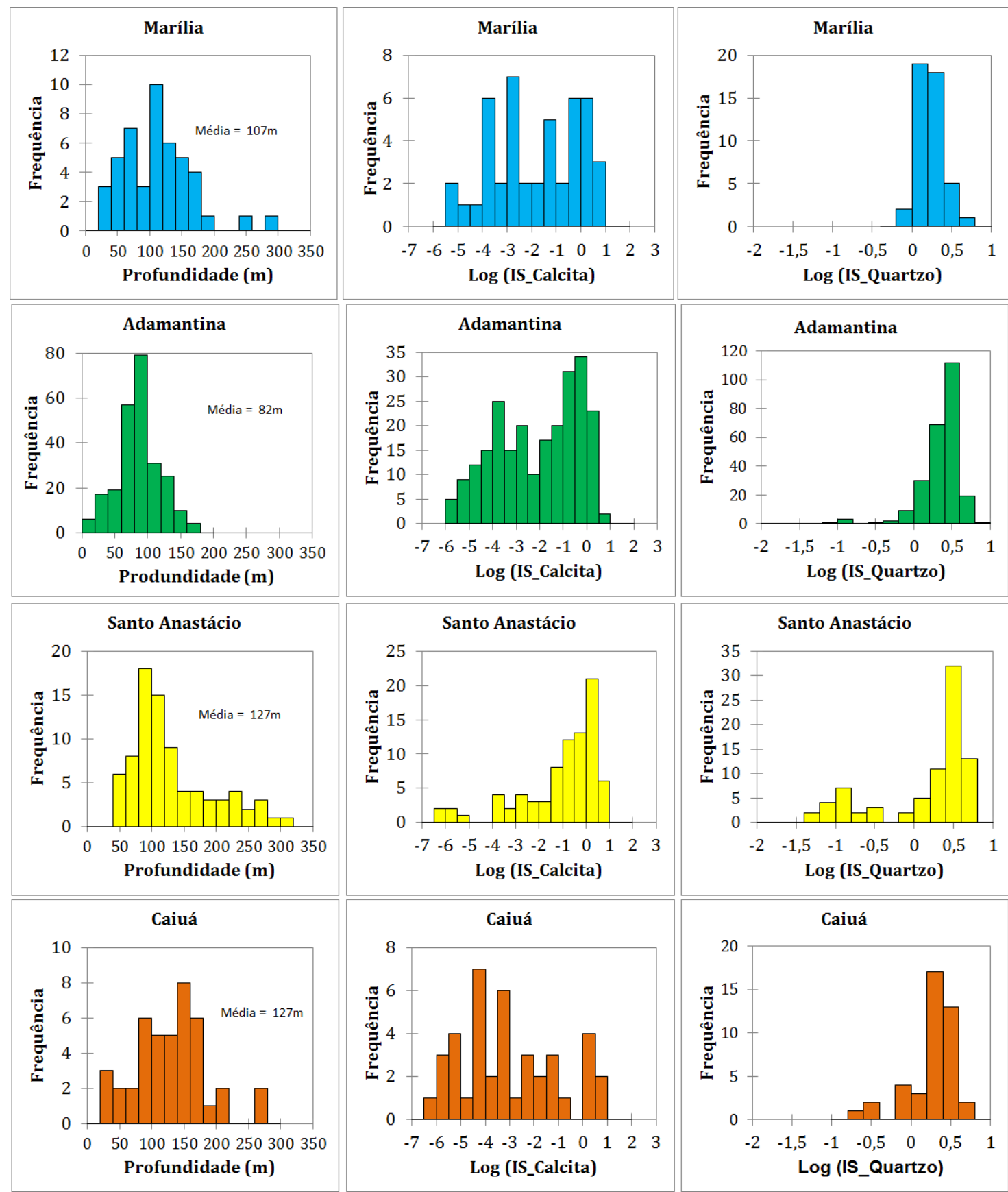

Figura 12 - Histogramas de profundidade e de grau de saturação das águas em relação a calcita e quartzo para 4 unidades aquíferas do SAB. Notar o predomínio de poços mais profundos na unidade aquífera Santo Anastácio. A proporção de poços de águas saturadas ou supersaturadas em relação à calcita $(\log (\mathrm{IS}) \geq 0)$ é maior nas unidades aquíferas Marília e Santo Anastácio. Quanto ao quartzo, a maioria dos poços estão saturados/ supersaturados. As amostras subsaturadas concentram-se no Aquífero Santo Anastácio e correspondem às amostras bicarbonatadas sódicas.

Figure 12 - Histograms of depth and degree of saturation of waters with respect to calcite and quartz for 4 aquifer units of SAB. Note the predominance of deeper wells in the Santo Anastácio Aquifer. The proportion of saturated or supersaturated waters with respect to calcite (log (IS) $\geq 0$ ) is larger for the Marília and Santo Anastácio Aquifer units. Majority of wells are saturated/ supersaturated with respect to quartz. Subsaturated samples are concentrated in the Santo Anastácio Aquifer and they correspond to sodium bicarbonate waters

Essas características hidroquímicas descritas para as águas das quatro unidades aquíferas estudadas são condizentes com as características lito-faciológicas do Grupo Bauru. A cimentação carbonática é abundante nas formações Marília e Santo Anastácio e se- 
cundariamente na Formação Adamantina. A unidade litoestratigráfica que se destaca desses três é a Formação Caiuá que é mineralogicamente mais rica em quartzo e com predomínio de fácies eólicas. Essa duas características são favoráveis à formação de águas pouco mineralizadas, em função de menor teor de minerais reativos, como os alumino-silicatos (e.g., argilo-minerais, feldspatos, micas) e baixo tempo de residência das águas que nela percolam.

Comparando-se as características hidroquímicas das águas classificadas pela análise de agrupamento e as das unidades aquífe- ras pode-se concluir que as composições das águas subterrâneas do Sistema Aquífero Bauru não são unicamente controladas pela estratigrafia e sim pelas características litofaciológicas. A tabela 4 mostra que a maior correlação entre elas ocorre com a unidade aquífera Caiuá, onde 76 \% das águas coletadas pertencem ao Grupo 1. O aquífero Santo Anastácio, por sua vez, tem suas águas predominantemente identificadas com os grupos 2 e 3 , enquanto que as águas dos aquíferos Marilia e Adamantina concentram-se, em maioria, nos grupos 1 e 2 .

Tabela 4 - Quadro resumo mostrando o número de poços pertencentes às unidades aquíferas Marília, Adamantina, Santo Anastácio e Caiuá nos conjuntos de amostras dos três grupos hidroquímicos determinados pela análise de agrupamento

Table 4 - Summary of the number of wells belonging to Marília, Adamantina, Santo Anastácio and Caiuá aquifer units for the three hydrochemical groups defined by the cluster analysis

\begin{tabular}{|c|c|c|c|c|}
\hline \multirow{2}{*}{$\begin{array}{c}\text { Grupos } \\
\text { Hidroquímicos }\end{array}$} & \multicolumn{4}{|c|}{ Aquíferos } \\
\cline { 2 - 5 } & Marilia & Adamantina & Santo Anastacio & Caiuá \\
\hline Grupo 1 & $22(48 \%)$ & $132(53 \%)$ & $20(24 \%)$ & $32(76 \%)$ \\
\hline Grupo 2 & $15(32 \%)$ & $84(34 \%)$ & $35(42 \%)$ & $9(22 \%)$ \\
\hline Grupo 3 & $9(20 \%)$ & $32(13 \%)$ & $29(34 \%)$ & $1(2 \%)$ \\
\hline
\end{tabular}

\section{CONCLUSÕES}

No estado de São Paulo, as águas subterrâneas do Sistema Aquífero Bauru são classificadas predominantemente como bicarbonatadas, segmentando-se em cálcicas e sódicas; em menor quantidade ocorrem águas cloretadas sódicas e sulfatadas cálcicas. O bicarbonato aparece como ânion principal, sendo o Aquífero Santo Anastácio mais alcalino que os demais do Sistema Aquífero Bauru. Os principais cátions são o cálcio e o sódio. As águas do Aquífero Caiuá são as menos salinas do $\mathrm{SAB}$, enquanto as águas do Aquífero Santo Anastácio são as mais mineralizadas.

As águas do Aquífero Santo Anastácio são mais ricas em cálcio na porção noroeste, e mais ricas em sódio na porção sudoeste da área de estudo. Esse fato deve-se possivelmente à dissolução de minerais sódicos, como a zeólita analcima, encontrada em testemunho de sondagem da unidade na porção sudoeste.

Em poços que explotam águas mistas do $\mathrm{SAB}$, estas apresentam similaridade química com águas do Aquífero Santo Anastácio devido aos filtros que em sua maior parte estão posicionados nesta unidade.

As amostras dos aquíferos Adamantina e Santo Anastácio na porção setentrional possuem características químicas similares, sendo o bicarbonato e o cálcio os íons predominantes.

Algumas amostras apresentam elevados teores de nitrato, muito deles ultrapassando o limite máximo permitido pela Portaria 2914/11 do Ministério da Saúde, indicando contaminação antrópica e estão preferencialmente associadas às águas coletadas em porções mais rasas, indistintamente dos grupos hidroquímicos e das unidades aquíferas. 


\section{AGRADECIMENTOS}

Os autores agradecem à FAPESP pelo auxílio (Projeto FAPESP n ${ }^{\circ}$ 2011/23785-
8) que possibilitou a realização deste estudo e ao CNPq pelo auxílio da bolsa PQ.

\section{REFERÊNCIAS}

ALMEIDA, M. A.; FERNANDES, L. A.; DANTAS, A. S. L.; SAKATE, M. T.; GIMENEZ, A. F.; TEIXEIRA, A. L.; BISTRICHI, C. A. E ALMEIDA, F. F. M. Considerações sobre a estratigrafia do Grupo Bauru na região do Pontal do Paranapanema no Estado de São Paulo. In: SIMPÓSIO REGIONAL DE GEOLOGIA, 3.,1981, Curitiba. Atas... SBG. v.1, p. 77-89.

APPELO, C. A. J.; POSTMA, D. Geochemistry, groundwater and pollution. 2. ed. Amsterdan: Balkema Publishers, 650p, 2005.

BARISON, M.R. Estudo hidroquímico da porção meridional do Sistema Aquífero Bauru no Estado de São Paulo. 2003, 153p. Tese (Doutorado em Geociências e Meio Ambiente) - Instituto de Geociência e Ciências Exatas, UNESP, Rio Claro - SP, 2003.

BJORLYKKE, K. \& EGEBERG, P. K. Quartz cementation in Sedimentary Basins. AAPG Bulletin, v.77, p.1538-1548, 1993.

BRANDT NETO, M., YAMAMOTO, J.K., TACHIBANA, J. E MATO, L.F. Sedimentos quaternários associados ao baixo vale do Rio Tietê. In: SIMPÓSIO REGIONAL DE GEOLOGIA, 1. 1977, São Paulo. Atas... São Paulo: SBG/SP, 1977. p.248-266.

BRASIL. Ministério da Saúde. Portaria 2914 de 12 de dezembro de 2011 - Dispõe sobre os procedimentos de controle e de vigilância da qualidade da água para consumo humano e seu padrão de potabilidade.

CAMPOS, H.C.S. Contribuição ao estudo hidrogeoquímico do Grupo Bauru no Estado de São Paulo. 1987. 158p. Dissertação (Mestrado em Geologia Geral e de Aplicação), Instituto de Geociências, Universidade de São Paulo, São Paulo, 1987.

COMPANHIA DE TECNOLOGIA DE SANEAMENTO AMBIENTAL - CETESB. Uso das águas subterrâneas para abastecimento público no Estado de São Paulo. SP: 48, 1997.

DEPARTAMENTO DE ÁGUAS E ENERGIA ELÉTRICA - DAEE. Estudo de águas subterrâneas, regiões administrativas 10 e 11: Presidente Prudente e Marília. São Paulo: v.1 e v.2, 1979.

DEPARTAMENTO DE ÁGUAS E ENERGIA ELÉ TRICA - DAEE. Estudo de águas subterrâneas, reÁguas Subterrâneas (2016) 30(2):224-245 giões administrativas 7, 8 e 9: Bauru, São José do Rio Preto e Araçatuba. São Paulo: v.1 e v.2, 1976.

DEPARTAMENTO DE ÁGUAS E ENERGIA ELÉTRICA - DAEE. Estudo de águas subterrâneas: região administrativa 6, Ribeirão Preto - SP, São Paulo: Geopesquisadora - Tahal, 2v., 1974.

HEM, J. D. Study and interpretation of the chemical characteristics of natural water. Alexandria: U.S.G.S., U.S. Geological Survey Water Suply Paper 2254. 272 p., 1985.

INSTITUTO BRASILEIRO DE GEOGRAFIA E ESTATÍSTICA - IBGE. Disponível em http://www.ibge.gov.br/home/estatistica/populacao/condicaodevida/pnsb/abastecimento_de_agua/abagua43.shtm. Acessado em 10/01/2013.

PARKHURST D.L. User's Guide to PHREEQC - a computer program for speciation, reactive path, advective transport, and inverse geochemical calculations: Denver: USGS, 104p. 1995. Water Resources Investigations Report. USGS 95-4227.

PAULA E SILVA, F. Geologia de subsuperfície e hidroestratigrafia do Grupo Bauru no Estado de São Paulo. 2003. 166p. Tese (Doutorado em Geociências). Instituto de Geociências e Ciências Exatas, UNESP, Rio Claro, 2003.

PAULA E SILVA, F.; CHANG, H.K.; CAETANOCHANG, M. R. E STRADIOTO, M. R. Sucessão Sedimentar do Grupo Bauru na Região de Pirapozinho (SP). Geociências. Rio Claro. v.25 (n.1), p.17-26, 2006.

PAULA E SILVA, F.; CHANG, H.K.; CAETANOCHANG, M.R. Estratigrafia de subsuperfície do Grupo Bauru (K) no Estado de São Paulo. Revista Brasileira de Geociências, v. 35, n. 1, p. 77-88, 2005.

PAULA E SILVA, F.; CHANG, H.K. E CAETANOCHANG, M.R. Perfis de referência do Grupo Bauru no Estado de São Paulo. Geociências. Rio Claro. v.22 (n.1), p.127-139, 2003.

PAULA E SILVA, F.; CHANG, H. K. E CAETANOCHANG, M. R. Caracterização das unidades neocretáceas da Bacia do Paraná na região de São José do Rio Preto (SP) com base na análise de perfis geofísicos e suas implicações estratigráficas. In: SIMPÓSIO SO- 
BRE O CRETÁCEO DO BRASIL, 6; SIMPÓSIO SOBRE EL CRETÁCEO DE AMERICA DEL SUR, 2, 2002, São Pedro. Boletim... 2002, p.345-349.

PAULA E SILVA, F. E CAVAGUTI, N. Nova caracterização estratigráfica e tectônica do Mesozóico na cidade de Bauru - SP. Geociências. UNESP. p.83-99, 1994.

PAULA E SILVA, F. E CAVAGUTI, N. Nova caracterização estratigráfica e tectônica do Mesozóico na cidade de Bauru - SP. In: SIMPÓSIO SOBRE BACIAS CRETÁCICAS BRASILEIRAS, 2, 1992. Atas... p.141-144.

RICOMINI, C., GIMENEZ FILHO, A., STEIN, D.P., ALMEIDA, F.F.M., PIRES NETO, A.G., DEHIRA, L.K., MELO, M.S. de, BRAGA, T.de O. E PONÇANO, W.L. Características da porção basal da Formação Caiuá no Noroeste do Paraná. In: SIMPÓSIO REGIONAL DE GEOLOGIA, 3. 1981, Curitiba. Atas... Curitiba: SBG/SP, v. 2, 1981. p. 34-48.

SOARES, P. C.; LANDIM, P. M. B.; FÚLFARO, V. J. E SOBREIRO NETO, A. F. Ensaio de caracterização estratigráfica do Cretáceo no Estado de São Paulo: Grupo Bauru. Revista Brasileira de Geociências. São Paulo. v. 10 (n. 3): p.177-185, 1980.

STANDARD Methods for the Examination of Water and Wastewater is a joint publication of the American Public Health Association (APHA), the American Wa- ter Works Association (AWWA), and the Water Environment Federation (WEF). 22a. Edição, 1368 p. 2012.

STRADIOTO, M.R. Hidroquímica e aspectos diagenéticos do sistema Aquífero Bauru na região sudeste do Estado de São Paulo. 2007. 103 p. Dissertação (Mestrado em Geociências e Meio Ambiente) - Instituto de Geociências e Ciências Exatas, Universidade Estadual Paulista. Rio Claro, 2007.

STRADIOTO, M. R.; CHANG, H. K.; CAETANOCHANG, M. R. Caracterização petrográfica e aspectos diagenéticos dos arenitos do Grupo Bauru na região sudoeste do Estado de São Paulo. Revista Escola de Minas. Ouro Preto. v. 61 (n. 4): p.433-441, 2008

STUMM, W. Chemistry of the solid-water interface: processes at the mineral-water and particle-water interface in natural systems. Wiley-Interscience publication. 1992.

SUGUIO, K.; FULFARO, V. J.; AMARAL, G. E GUIDORZI, L. A. Comportamentos estratigráfico e estrutural da Formação Bauru nas regiões administrativas 7 (Bauru), 8 (São José do Rio Preto) e 9 (Araçatuba) no Estado de São Paulo. In: SIMPÓSIO REGIONAL DE GEOLOGIA, 1, 1977, São Paulo. Atas... p. 231-247.

VIEIRA, P. C. Sugestão para estudo de captação de água subterrânea no Grupo Bauru: considerações tectônicas. Revista do Instituto Geológico - IG, São Paulo - SP. 2 (2): p 5-16, 1981. 